\title{
Hacia la educación a distancia en la bibliotecología: algunas pro- puestas en México y en España
}

\author{
Juan Carlos Marcos Recio *
}

Artículo recibido:

1 de diciembre de 2004.

Artículo aceptado:

5 de mayo de 2005.

\section{RESUMEN}

El compromiso docente de un gobierno se hace real cuando los resultados del sistema educativo alcanzan grados importantes de calidad y eficiencia en la sociedad. Para ello se requiere un conocimiento previo de los componentes sociales, económicos y, sobre todo, educativos en los tres niveles principales: institución educativa, docentes y alumnos. Se evalúan los estudios actuales y se presenta una evolución hacia la educación a distancia determinando sus ventajas e inconvenientes. El punto de partida es la situación actual de los recursos utilizados en la educación mexicana en bibliotecología, tomando como referencia algunas universidades españolas que trabajan estas herramientas. Se trata de cursos, asignaturas o parte de ellas en métodos a distancia con el fin de conocer cuáles son las aplicaciones tecnológicas con las que cuenta la bibliotecología.

* Centro Universitario de Investigaciones Bibliotecológicas de la UNAM, México. jmarcos@cuib.laborales.unam.mx

INVESTIGACIÓN BIBLIOTECOLÓGICA, Vol. 20, Núm. 40, enero/junio, 2006, México, ISSN: 0187-358X. pp. 73-120 
Palabras Clave: Recursos docentes; Bibliotecología; Educación; Educación a distancia; Docentes; Alumnos.

\section{ABSTRACT \\ Towards distant education in library science: some proposals for Mexico and Spain \\ Juan Carlos Marcos-Recio}

The educational commitment of a government becomes real when the results of the educational system reach important degrees of quality and efficiency in the society. But previous knowledge of social, economic and, above all, educational components in all three main levels: educational institution, teachers and students, is required. Current studies are assessed and a possible evolution towards e-learning is presented determining advantages and disadvantages. The starting point is the current situation of resources used in Mexican library science education, with reference to some Spanish universities already working with these tools. The aim is to obtain information about courses, subjects and other elements related with distant education in order to know which technological applications are used by library science.

Keywords: Educational resources; Library science education; E-Learning; Teachers; Students.

"Para que las tecnologías no engañen ni nos dominen bay que pensarlas a fondo, es decir, no perder de vista en qué consisten, independientemente de lo que hagamos con ellas. Debería ser enseñada antes que aplicada. La enseñanza debería procurar que las tecnologías susciten tanto asombro como la propia realidad natural, porque ésta es más compleja que lo que la imaginación puede alcanzar".

José Luis González Quirós. CSIC

$\infty$

"No more pencils, no more books, no more teachers' dirty looks. Forget that. It's time for even the most seasoned IT professionals to head back to school". (No más lápices, no más libros, no más miradas malévolas de los maestros. Olvídense de eso. Es tiempo de que aun los profesionistas más experiementados de las tecnologías de la informnación, regresen a la escuela).

Von de Raymond Dran 


\section{INTRODUCCIÓN}

- 1 horizonte de la educación no debe perderse nunca. El futuro de una sociedad depende del camino que recorran sus ciudadanos en la escuela y en la universidad. De ahí la importancia que cada gobierno le da a la educación, consciente de que si conserva la cultura y la tradición y, sobre todo, si la mejora y la enriquece, esa nación seguirá la senda del bienestar. No hay progreso sin educación. Como tampoco lo hay sin esfuerzo, investigación, desarrollo y el trabajo bien hecho de cada día. Lograrlo implica una participación de toda la sociedad. La educación es una tarea colectiva. Se dice muchas veces, se cumple con el dicho mucho menos. Los padres envían a sus hijos al colegio creyendo que de allí saldrán unos niños disciplinados y con una carga de saber en su mochila. Luego los dejan en la universidad para que se hagan hombres y aprendan una profesión. Sin embargo, el sistema no funciona o funciona mal cuando una de las tres partes (padres, educadores y alumnos) no cumple con su compromiso.

En ocasiones los tres polos principales actúan en consecuencia y sin embargo los resultados siguen sin ser los deseados. ¿Qué falla en el proceso educativo? ¿Por qué los alumnos se sienten desmotivados? ¿Quién debe asumir los errores? ¿Cómo se han de reconducir esas situaciones de desencanto en los profesores y en los alumnos? ¿Qué hace el país para mejorar su educación? ¿Y la universidad? Son tantas las interrogantes que se plantean que si se resuelve al menos una porción de ellas se habrá recorrido una buena parte del camino hacia la educación de la sociedad misma.

El punto de partida de la educación pasa por solventar tres grandes retos que son: una cobertura con equidad, la calidad de los procesos educativos y de los niveles de aprendizaje, y la integración y el funcionamiento del sistema educativo. En este sentido, México se halla inmerso en el Plan Nacional de Desarrollo 20012006 y necesita cambios profundos para preparar una educación tanto por lo que toca a contenidos como a métodos y también con las actuaciones de profesores y alumnos. El objetivo de este Plan es ofrecer información de calidad para mejorar la sociedad, siempre dentro de un ámbito de competitividad y equidad entre los diferentes estados. El plan viene delimitado con la siguiente formulación:

[...]la educación es el eje fundamental y deberá ser la prioridad del gobierno de la República. No podemos aspirar a construir un país en el que todos cuenten con la oportunidad de tener un alto nivel de vida si nuestra población no posee la educación que le permita, dentro de un entorno de competitividad, planear su destino y actuar en consecuencia. ${ }^{1}$

1 Véase Documentos en línea de la Secretaria de Educación Pública:

http://sesic.sep.gob.mx/docsenlinea/pne/introduccion/introduccionIII.htm [Consultada:31-05-2004] 
El sistema educativo tanto en México como en España ha de dar un giro profundo en sus estructuras. Tendrán que ser, desde luego, más flexibles y permitir decisiones que se puedan ejecutar en un breve plazo de tiempo. Se les demandará también a ambos ámbitos educativos que hagan un esfuerzo por abrirse a nuevos sistemas de aprendizaje, entre ellos la educación a distancia, y esto en todos los niveles educativos, ya que se pretende llegar a la "sociedad del conocimiento" 2 por el camino de la innovación educativa. Las tecnologías de la información y comunicación seguirán abriendo nuevas perspectivas para la educación a distancia, y permitiendo atender, de manera más amplia y mejor, las necesidades educativas, cada día más urgentes y diversas de quienes no han podido terminar su educación básica, pero también las de los egresados de niveles superiores.

Este proceso se dirige a dos frentes de forma significativa: profesores y alumnos. Los primeros se han de implicar en nuevos procesos de aprendizaje, y realizar cursos de capacitación y formación en Tecnologías de Información y Comunicación (TIC). Como la educación del futuro requiere aprender a compartir recursos, los profesores han de saber interactuar con otros docentes y con los alumnos, hasta el grado de hacer necesaria una aptitud para fomentar la comunicación interpersonal y el trabajo en grupo. Habrá de mostrar el docente un talante abierto hacia la tecnología como herramienta de ayuda para su creatividad y una enseñanza cada vez más alejada del aula, la cual deja de ser el principal espacio de aprendizaje para convertirse en un factor de ayuda en la educación. La actividad escrita, la clase magistral y el aula, se presentan ahora como actividades de apoyo para una educación que tiene como eje principal la interacción entre profesores y alumnos, entre alumnos y sus propios compañeros, y entre varios profesores. Por lo que respecta a los alumnos, éstos habrán de llegar a la universidad con una formación tecnológica elevada que les permita seguir estudios interactivos con los que accederán a programas impartidos de forma mixta: una parte en clase y otra a distancia. Se les propondrán también actividades y prácticas para desarrollar en su tiempo libre y que se hacen de forma colectiva, en grupos de trabajo que compartirán la información y los logros obtenidos por los propios grupos.

Todo eso necesita mostrar resultados aceptables para la sociedad. Así, se demandará de los docentes una respuesta clara y diferenciada, que le dé calidad a la información y que atienda de forma adecuada las necesidades de

2 La innovación educativa en la sociedad del conocimiento. Enfoque educativo para el Siglo XXI. Plan Nacional de Desarrollo. 
los estudiantes. Durante un tiempo habrá que experimentar con otras formas educativas que puedan garantizar el acceso a los estudios para todas las personas, y los recursos suficientes para que se imparta una docencia que implique garantías por parte del docente. Ese proceso continuo de mejora de la docencia, que utilizará necesariamente la tecnología, ha de ser reconocido por las autoridades educativas, sobre todo en las primeras fases, pues el tiempo consumido por parte del profesor será elevado.

Conviene recordar aquí un reciente estudio de IBM en el que se pronostica un triple salto en la educación global en los próximos años (hasta el 2013) y en el que se invertirán 4,5 trillones de dólares. Por su parte, el Banco Mundial cree que el número de estudiantes de enseñanza superior se duplicará y pasara de 70 a 160 millones en el 2025. ${ }^{3}$ De esta forma, algunos autores piensan que en una década, las actuales universidades se habrán convertido en una especie de dinosaurio en extinción, pero esa expresión no se aplicará a todas ellas.

\section{CONCEPTO DE EDUCACIÓN: EVOLUCiÓN HACIA LOS SISTEMAS A DISTANCIA}

El ambiente que rodea a la educación (institución, profesores, alumnos, personal administrativo, etcétera) forma parte de un colectivo dinámico. La mayoría de los estudios transcurren cuando la persona es más joven, cuando la actividad es más fuerte y cuando las ideas fluyen con más rapidez. Ese caldo de cultivo permite hacer investigaciones, enfrentarse a retos que parecían irresolubles o mejorar algún aspecto social que ha sido olvidado por las autoridades. Son años de trabajo, rendimiento y aproximación a las ideas fundamentales de la cultura que abren luego el camino hacia la madurez intelectual y profesional.

Las Tecnologías de la Información y la Comunicación (TIC o ICT por sus siglas en inglés) les ofrecen alternativas y actividades complementarias a los profesores para que impartan su docencia, y obtengan otros recursos informativos y los empleen en su quehacer diario. La educación del siglo XXI evolucionará en esta primera década de forma considerable, pero esa implantación habrá de dejar un sedimento en los docentes, una reflexión oportuna para sentar nuevas bases de trabajo que se irán cimentando sobre los aciertos y errores de estos primeros años en los que la educación a distancia se está abriendo camino en una gran mayoría de las instituciones educativas. Habrá que estar atentos para que la brecha digital no rompa más las diferencias que 
la educación industrial dejó (época que coincide con el desarrollo pleno de libros y medios de comunicación), ya que podrían ser muy pocos los países que luego tendrían acceso a una nueva forma de educar.

Se entiende a la educación como la ciencia que le permite a una sociedad acceder a la cultura y a una formación individual que luego aplicará en su beneficio. Se trata de un viaje de ida y vuelta: se le ofrecen al alumno ideas, contenidos y experiencias, que luego éste aplicará en su quehacer profesional. Para ello, contará con la experiencia del profesor, las aportaciones de los investigadores, su formación personal lograda a través de lecturas y conversaciones, y las herramientas de apoyo con las que llegará al mundo del saber. María Moliner dice que "educar (del lat. educare) es preparar la inteligencia y el carácter de los niños para que vivan en sociedad". ${ }^{4}$ De esta definición se desprende que la educación se aplica principalmente a los niños, cuando en los tiempos presentes esa idea es tan sólo el punto de partida. Por su parte, Noe Jitrik ${ }^{5}$ aplica el concepto de socialización, ya que para él educar es trasmitir y recibir conocimientos tanto teóricos como prácticos. Moore ${ }^{6}$ es uno de los autores que mejor ha precisado otro de los conceptos significativos para este artículo y para la sociedad actual: la educación a distancia. Para él la implicación profesor-alumno y sus relaciones son la base que sustenta esta educación:

la enseñanza a distancia es el tipo de método de instrucción en que las conductas docentes acontecen aparte de las discentes, de tal manera que la comunicación entre el profesor y el alumno pueda realizarse mediante textos impresos, por medios electrónicos, mecánicos, o por otras técnicas (Moore, 1972).

En la mayoría de las definiciones presentadas aparece un denominador común: acciones para el aprendizaje de forma continua. El ser humano ha revalorizado su formación. La separación física del profesor con el alumno en los estudios que se perfilan de cara al futuro será traumática si no se establecen mecanismos de trabajo que sean adaptables para ambos. El corte de ese cordón umbilical se ha de hacer cuanto antes para que, una vez efectuado, el profesor se adentre sin miedo en el sistema a distancia, prepare sus materias y las ponga a disposición de los alumnos.

4 María Moliner, Diccionario de uso del español, Madrid: Gredos, 2001 - p. 1055.

5 Noe Jitrik, Glosario de Educación Superior, México: Comité Interinstitucional para el Glosario y el Tesauro de Educación Superior, 1986 - p. 62 (Mecanografiado)

6 M. G. Moore, "Learner autonomy: the second dimension of independent learning", en $\mathrm{Co}$ llection of Conference Papers, Warrenton, 1972. 


\section{Desarrollo de la educación: Destino Del Siglo XXI}

Con relativa frecuencia se piensa que la educación es un sistema cerrado y poco dado a cambios y, menos aún, a la experimentación. Sin embargo, a lo largo de los siglos ha sido un campo en el que no se ha dejado de investigar para aplicar luego esos resultados al ámbito profesional. Desde el método griego que consistía en pasear junto al maestro, quien interpelaba con dudas a los alumnos, hasta la presencia de la enseñanza a distancia a través de la tecnología, se han producido pequeñas revoluciones en cada era: edad media, renacimiento, época de la razón y la ilustración francesa, modernismo, etcétera.

¿A qué se tienen que enfrentar los profesores en la actualidad? ¿Cómo y con qué herramientas cuentan? ¿La sociedad apoyará definitivamente los sistemas educativos a distancia? Todas estas interrogantes no tienen una respuesta clara, tan sólo se percibe en el horizonte un compromiso de las instituciones, de los docentes y, en menor medida, de los alumnos, quienes asumen como válidos los sistemas que encuentran en su llegada a la universidad. La educación en el siglo XXI será sobre todo información.

Cuando un profesor enseña, trasmite conocimiento; es decir, ofrece información para que a su vez quien recibe esos contenidos los pueda utilizar en su beneficio. Si se busca el origen de la palabra información, obtenemos esa justificación que sirve de marco al docente para ofrecer ideas, experiencias, ejemplo personal, etcétera, y todo eso es la educación.

Aunque las computadoras están cada día más cerca de las personas, la educación a distancia es un elemento reciente en la sociedad. Durante años, la información que servía como elemento de comunicación entre países se desarrollaba a través de cartas y embajadores. A lo largo de la edad media y en los siglos posteriores, la educación de carácter religioso se ofrecía mediante escritos que llevaban de un monasterio a otro los religiosos. Eran mensajeros que transportaban ciencia que habían escrito o copiado otros monjes. Luego, aparecieron los periódicos y revistas como soportes de información. También durante muchos años sirvieron como elemento de aprendizaje para la lectura y consecuentemente la educación de sociedades donde los libros eran escasos. Así, antes de la llegada de los sistemas en línea, el principal elemento de educación a distancia era la carta; algunos autores (Horton, 2000) sostienen que uno de los pioneros de este tipo de sistema de educación fue Sir Isaac Pitman, allá por 1840, cuando organizó por correspondencia unos cursos de estenografía.

El siglo XIX se ha considerado como el de los grandes inventos (ferrocarril, telégrafo, radio, cinematógrafo, automóvil, máquinas de escribir y coser, 
cámara de fotos, lámpara eléctrica, etcétera), aunque algunos se desarrollaron o completaron a lo largo del siglo XX. Esa tecnología que actuaba de forma limitada se transfiguró años después en una acción revolucionaria. Cada nuevo descubrimiento les ha abierto las puertas a muchos otros. Una diversificación que ahora se hizo realidad gracias a los sistemas de comunicación.

En el siglo XX se mejoró de forma notoria la transmisión del conocimiento, sobre todo a través de revistas científicas, de tal forma que los inventos y los descubrimientos se dieron a conocer de forma inmediata, incluso a veces sin estar seguros de si con ello se abrían posibilidades para que otros no se adelantaran. Este sistema de trabajo entre científicos posibilitó un nivel de competitividad mayor y esto hizo que las distancias se fueran acortando. Lo difícil es poder seguir el movido ritmo que imponen las tecnologías. Así lo explica Miguel Pérez Subías ${ }^{7}$ en su discurso de apertura de Internet 99: IV Congreso Nacional de Usuarios de Internet:

La tecnología va más deprisa que las personas, por ejemplo el teléfono tardó 40 años en conseguir 10 millones de usuarios, el fax tardó 10 años. Los móviles 5 años y en Internet se ha llegado a los diez millones en poco más de un año y medio.

Ya en pleno siglo XXI la idea principal apunta a trabajos conjuntos entre los diferentes soportes que emplea la tecnología. La utilizada en el siglo XX, incluyendo radio y televisión educativa, sólo servirá ahora como referencia en el ámbito de la educación superior. El sistema educativo sigue siendo uno, pero los soportes utilizados para su desarrollo muchos: videoteca, satélite, Internet, pedidos bajo demanda, la telefonía celular, etcétera.

Ante esta situación hay que actuar con cautela, pues no todos tienen las mismas motivaciones frente a la tecnología. Algunos se sienten empujados cuando no han asumido a nivel personal las ventajas que ésta ofrece. No se trata de entregar un paquete conjunto pensando en que ahí entran todos los profesores y todos los alumnos. Hay que ir perfilando y delimitando las asignaturas, sus contenidos, su enfoque y, sobre todo, su adaptación a los alumnos.

Las primeras décadas de este siglo serán de convivencia entre los sistemas ya utilizados y los que se están experimentando en algunas universidades virtuales. Ni todo lo soluciona la tecnología, ni tampoco eran tan malos los sistemas que hicieron avanzar la sociedad hasta el importante desarrollo de comienzos del tercer milenio. La anticipación es la clave del éxito, pero llegar antes no significa que los estudios que se ofrezcan sean mejores. Habrá

7 Miguel Pérez Subías, “Acto de inauguración del Internet 99: IV Congreso Nacional de Usuarios de Internet”, Madrid, 3-6 de febrero de 1999. 
que complementar mientras tanto la docencia en las aulas con la impartida a distancia; es decir, adoptar sistemas mixtos que les permitan a los alumnos adaptarse a los nuevos horarios que la universidad les ofrece. Avanzada ya la primera década del nuevo siglo, se perfila un camino a seguir: estudios a distancia sí, porque la educación exige una actualización por parte de los profesionistas, pero estudios con alumnos presentes también porque la formación a la que tendrán acceso será más guiada y obtendrá mejores resultados siempre y cuando se cumplan las reglas ofrecidas por el docente. Hay que pensar también que no todos los alumnos tendrán la suficiente capacidad para el autoaprendizaje por lo que necesitarán de profesores que los orienten y les marquen el camino que han de seguir.

\section{RECURSOS PARA LA EDUCACIÓN A DISTANCIA}

Las personas se esfuerzan constantemente para que cada logro, cada avance y cada paso adelante sirvan para sustentar ese edificio que se llama sociedad. A lo largo de la historia la mayoría de los inventos se han planteado como un retroceso social porque las máquinas hacen cosas que el hombre deja de hacer. Ese temor seguirá latente con cada nuevo descubrimiento, forma parte del devenir adaptarse a cada nueva situación ante los retos que imponen las tecnologías y el acoso y el desplazamiento de la persona; frente a la computadora sólo tenemos la adaptación. En la educación ha sucedido algo parecido, sobre todo a lo largo del siglo XX, cuando el aumento de actividades educativas impulsadas por los gobiernos obtuvo cotas impensables hasta entonces. El primer paso ya está dado en una mayoría de países, puesto que han alcanzado un alto nivel de lucha contra el analfabetismo y logrado índices próximos al 90-95\% de escolarización.

La presencia de las Tecnologías de Información y Comunicación (TIC) en la última década del siglo Xx le abrió las puertas a modelos de educación nuevos, creados con su ayuda pero basados en sistemas tradicionales que en ocasiones eran difíciles de aplicar. En efecto, no todos los contenidos se pueden trasvasar de la forma presencial a una educación a distancia. Al principio los planteamientos de la educación actual -en torno a 1990-1995- se estructuran incluyendo materias educativas y siguiendo formas mixtas que en su mayoría se desarrollan en el aula universitaria. Se apuesta por una continuidad en la forma de impartir la docencia pero se introducen prácticas que se evalúan y se comentan en la clase presencial. De ahí a la actualidad han aparecido mejoras constantes en cada curso, unas impuestas por la propia universidad, otras basadas en el trabajo de algunos departamentos, y las últimas, han sido 
desarrolladas por ciertos profesores que no encuentran en su institución un sistema de trabajo más acorde con la metodología actual que demandan los alumnos.

En una década se pasa de unos comienzos titubeantes a un trabajo metódico y sistemático por parte de algunas universidades, siempre valorando los pasos intermedios, los errores cometidos en los cursos impartidos y las mejoras que se hacen antes de comenzar el siguiente. No se trata de separar; al contrario, unir es la respuesta inteligente para que el sistema dé mejores resultados. Así, educación presencial y educación a distancia no se deben presentar enfrentadas, ni tampoco como rivales que intentan conseguir un mercado de alumnos que ofrece cada vez más opciones educativas. Se debe precisar desde el principio que ambas persiguen el mismo objetivo: enseñar, aprender y formar a las personas de una o muchas culturas, en una o muchas culturas. No cambia el sistema, lo único que varía es el medio en el que actúan los docentes y los alumnos.

\section{Nuevos ambientes de aprendizaje}

Está claro que se trata de un nuevo ambiente de aprendizaje apoyado en dos aspectos: gran diversidad cultural y nuevas estructuras lingüísticas. La primera de ellas pone en escena alumnos de diversos países. En este sentido se produce un enriquecimiento cultural porque se discutirán temas en los que participarán alumnos de Madrid, El Cairo, México D.F. o Melbourne, y cada uno de ellos ofrecerá una visión sobre la materia educativa pero añadirá una perspectiva más: la realidad social, política, económica, etcétera, de su país. Esa diversidad modificará sin duda las futuras relaciones profesionales de estos estudiantes, que dentro de la globalidad empresarial y antes de iniciar su proyección laboral, han tenido contacto con casos prácticos de diversas empresas en el mundo.

El otro gran marco de desarrollo es el lenguaje. Aquí está uno de los mayores retos de estos estudios. Llegar más lejos, más rápido y mejor, podría ser el lema de una o varias universidades que ya estén impartiendo docencia a distancia, pero todas se encuentran con diferentes idiomas. La tendencia podría ser a asociarse entre comunidades con el mismo lenguaje; es decir, España con Latinoamérica o Inglaterra con sus ex colonias. Pero, entonces se puede romper el proceso referido con anterioridad, en el que la diversidad cultural es ineficaz porque falla el idioma entre Madrid y El Cairo. Sin embargo no existen soluciones eficaces para los dos planteamientos previos porque estos estudios se encuentran en una fase de experimentación. Generar recursos para uso de la educación no significa poner contenidos en Internet y esperar, eso pudo ser al principio, hoy la interacción es el elemento que mejor define 
estos estudios. En ningún caso educación y tecnología son excluyentes, más bien se complementan para darles servicio a los alumnos y permitir un desarrollo expositivo más dinámico por parte del profesor. La clase magistral se quedará en el futuro para jornadas, eventos, exposiciones, presentaciones y muestras de un día, donde los ponentes ofrecen varias ideas de una realidad que sirve como punto de partida para el debate posterior.

De muchas formas se conoce la educación que utiliza recursos tecnológicos: educación virtual (la más común y aceptada junto a la educación a distancia), teleeducación, teleaprendizaje, teleformación, educación online, educación sin aulas, educación a través de la web, hasta llegar al e-learning o aprendizaje electrónico o a través de Internet donde entran en juego, intranets y extranets, pero también la tecnología de los satélites, la televisión y el DVD interactivo. Tres son los pilares -Figura 1- en los que se sustenta la educación a distancia: los equipos de trabajo docente, compuestos por profesores y alumnos, una normativa internacional y un desarrollo informático que les permita trabajar a profesores y alumnos.

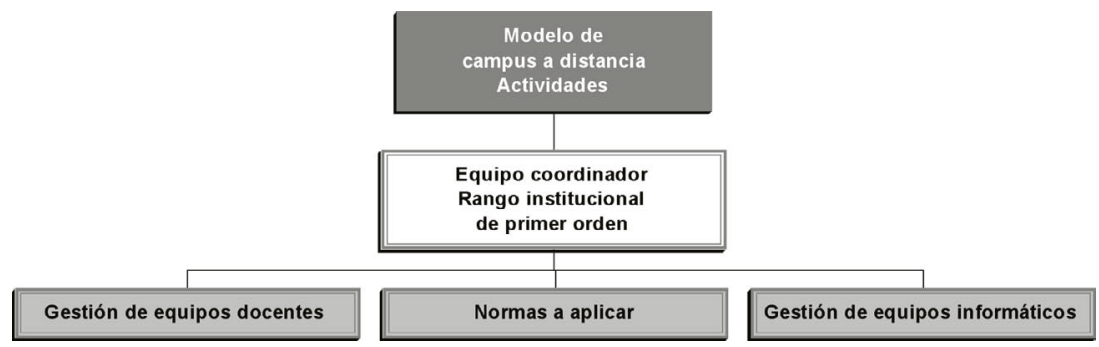

Figura 1. Tres ejes principales sobre los que bascula la educación a distancia

Al final, sea cual sea el nombre que se use, todos acaban por tener su acción dentro de Internet y otras redes similares, como el futuro tipo Internet II; sitios donde la docencia y la investigación no se vean asaltados constantemente con publicidad o con páginas de diversos contenidos alejados totalmente de la educación. Importa poco el nombre o el soporte a través del cual llegue, lo que será decisivo para su asentamiento será la combinación de los recursos tradicionales con las innovaciones de la tecnología que le permitirán al profesor mostrar su saber en varios frentes. Así, profesores y alumnos están encontrando fórmulas de acercamiento para hacer uso de la tecnología en sus clases, donde las funciones principales serían las siguientes:

1. Profesor: crear contenidos, evaluar la formación, ofrecer una bibliografía más amplia y actualizada y, sobre todo, reutilizar una parte de 
la docencia para cada curso. Recortar el tiempo de trabajo, fomentar grupos de trabajo con otros profesores del área temática, y producir un intercambio fluido de contenidos en la misma especialidad. Los metadatos aportarían mayores y mejores contenidos dentro de la red.

2. Alumnos: acceder a más cursos y más baratos, no desconfiar al ver que varias universidades usan los mismos programas de trabajo, acceder a diferentes asignaturas en una o varias universidades, ya que éstas emplearán el mismo estándar y habrá seguramente una mayor compra y venta de contenidos educativos.

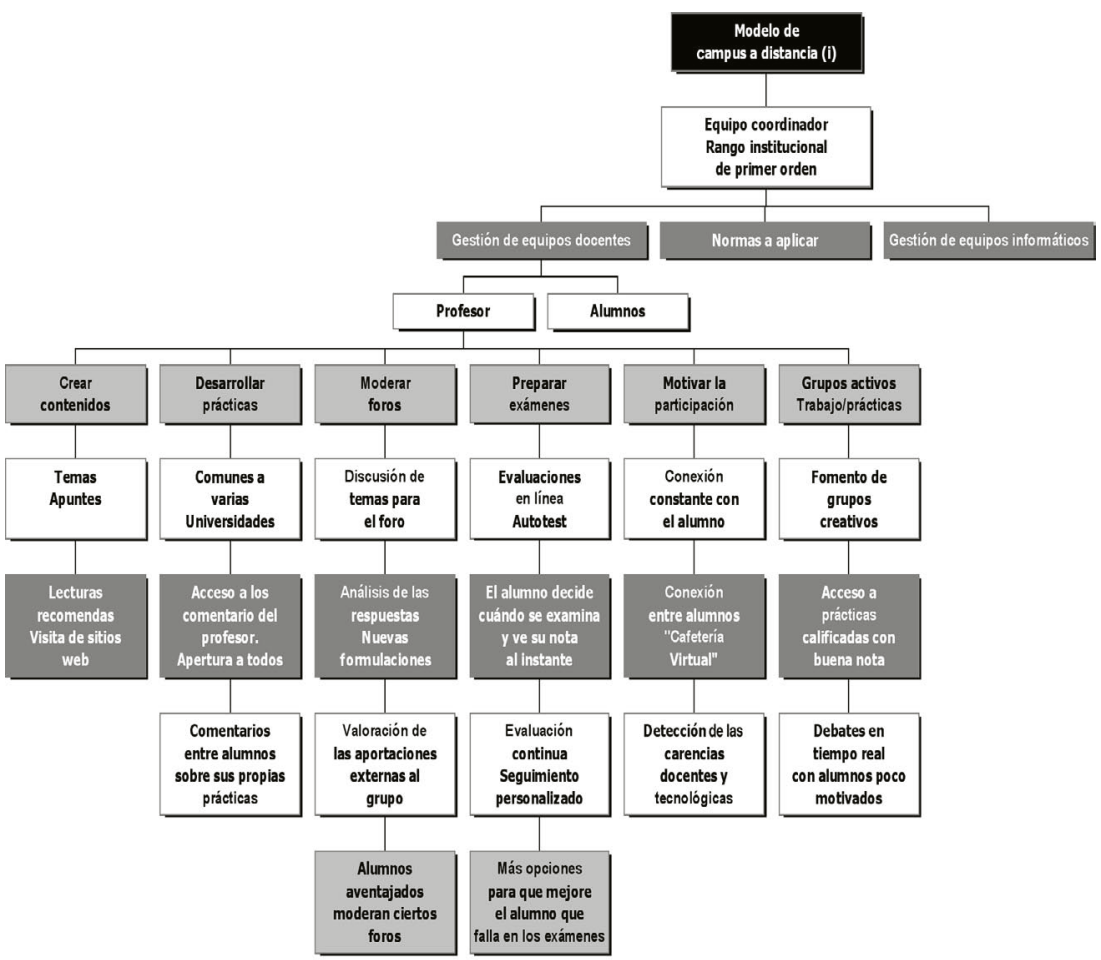

Figura 2. Principales funciones del profesor en un sistema a distancia 


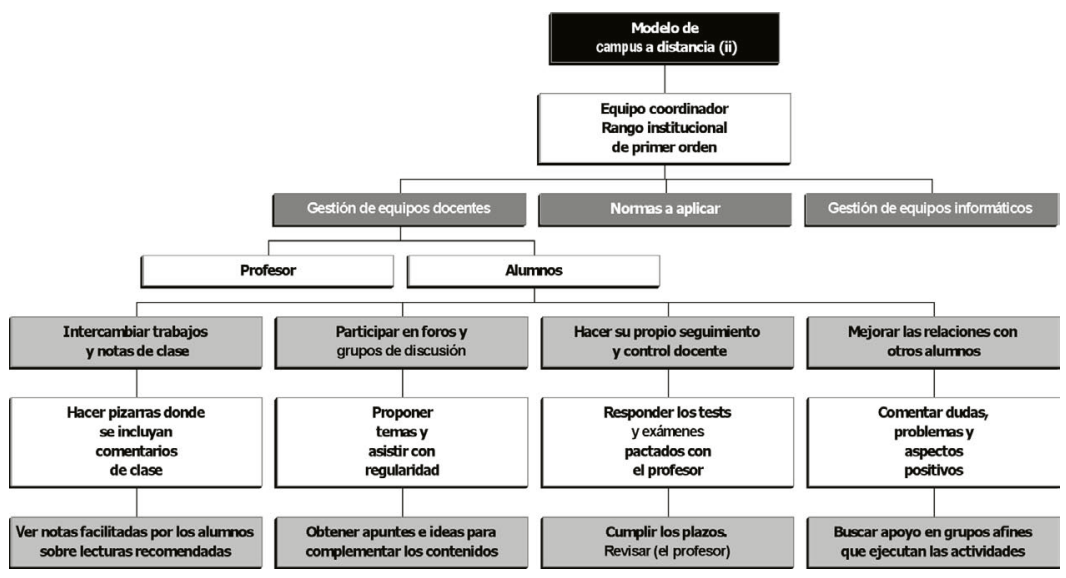

Figura 3. Tareas que desarrolla el alumno en educación a distancia

\section{Ventajas de la educación a distancia}

Los pilares en que se sostiene la educación a distancia son cambiantes, como la misma educación. Lo que durante un tiempo se considera una ventaja, luego puede transformarse en inconveniente. Cerrar el círculo impone dejar fuera criterios que han servido durante años a los académicos pero que se han visto desbordados por el tiempo. Éstas serían algunas de las ventajas:

- Se acaban los problemas de espacio físico y se limita la masificación a la que están sometidas algunas universidades centrales en algunos países. Se diversifican los espacios, ya que no es necesario que acudan todos los alumnos, ni siquiera todos al mismo tiempo. Se pueden pactar tutorías presenciales en diferentes momentos.

- Se flexibilizan los estudios. No se requiere acudir todos los días y en el horario que ha determinado la universidad. Se puede combinar mejor el estudio con el trabajo y la docencia porque el alumno es quien decide la hora en que participa en sus asignaturas.

- El tiempo cambia su función. Se hacen programas muy variables para darle oportunidad a estudiantes que disponen de poco tiempo. Así, ese estudiante se ahorra tener que ir a su centro y consumir en ello una o dos horas de desplazamiento.

- Los procesos económicos se hacen más baratos. Hay mayores costos iniciales, pero disminuyen progresivamente cuando se ha puesto el sistema en marcha, sobre todo porque los costos se pueden repartir entre varias universidades que utilicen la misma herramienta de trabajo. 
- La actualización de los estudios se vuelve una especie de formación continua a la que el profesional o el trabajador va accediendo en función de sus necesidades o mejoras profesionistas. Sólo se propone esta actualización, se ofrecen opciones para que se regrese a los estudios sin tener que hacer un esfuerzo adicional.

- Se da una autoformación del alumno. Algunos autores utilizan el concepto de autodisciplina. El alumno deberá acostumbrarse a un proceso de estudio diferente al que utilizó en sus estudios tradicionales. Necesitará aprender a repartir su tiempo entre el estudio y su trabajo, el cual también en algunos casos hará a distancia.

- Resolución de dudas en tiempo real. En los sistemas tradicionales el alumno pregunta en clase una duda o acude a tutoría para resolverla. Esa situación ha cambiado recientemente y la interactividad es mayor, lo que le permite al alumno una aproximación en tiempo real al profesor.

- Al final habrá más oportunidades educativas para todos y en diferentes niveles, ya que la educación superior llegará a sitios donde no haya una universidad.

\section{Desventajas de la educación a distancia}

Si bien algunas instituciones llevan ya más de una década de haber instaurado la docencia a distancia, la mayoría de ellas sigue estando en fase de implementación y pruebas. Por eso resulta a veces arriesgado adelantar desventajas de estos estudios, pues ciertas pruebas que han salido mal se pueden ir mejorando y revisando para el siguiente curso. En todo caso, algunas de las desventajas serían:

- Acceso a la tecnología. No todos los países están en disposición de ofrecer a los estudiantes una red fluida para comunicarse con su profesor, para descargar los ficheros o para intercambiar y realizar trabajo con sus compañeros.

- Precio de los servicios. Algunos proveedores siguen cobrando tarifas altas, lo que sumado a la compra de un equipo y a su mantenimiento, más el pago de conexión, deja sin opción a personas con preparación y ganas de hacer este tipo de estudios.

- Exigencias técnicas de muy alto nivel para los alumnos. Ésta es una formación personal del alumno, pero para ello se le exigen ciertas destrezas en la informática, el conocimiento de normas internacionales aplicadas a los sistemas informáticos, trabajar con varios programas de computación, etcétera. Ante esta situación, y a pesar de que 
cada día todo esto es más sencillo, el alumno puede llegar a sentirse impotente y decidir abandonar los estudios o cambiarlos por el método presencial.

- Formación tecnológica de profesores y alumnos. Se trata de un paso previo necesario para que no se rompa la dinámica de trabajo. A nivel de profesores, la universidad avalará esa formación mediante cursos sobre tecnología en general y también sobre la herramienta de trabajo que se emplea en la docencia. Asimismo los alumnos recibirán, en su nivel, otros cursos de orientación y casos prácticos para resolver las dudas que se planteen en su uso.

- Falta de bibliografía y recursos informativos. Los contenidos que ofrecen algunos cursos o asignaturas en los estudios a distancia son limitados. Desde hace dos décadas la mayoría de los recursos que se manejan están digitalizados, pero ¿qué sucede con los libros, revistas y documentos en general, que no lo están? El alumno se pierde una parte importante si no complementa sus estudios a distancia con la presencia continua en una biblioteca o centro de documentación.

- Muchos de los documentos que se manejan en un curso cuando éste inicia, ya no están en el siguiente. Algunos contenidos de Internet desaparecen y nadie sigue su rastro. Este inconveniente es menor si se dispone de un servidor en el cual almacenar estos contenidos, pero esto ya exige un trabajo complementario.

\section{Tecnología informática al servicio de la educación}

La sociedad está inmersa en un proceso global que afecta a todas las naciones. Muchas de las funciones que desarrollan los Estados van más allá de sus fronteras. Las tareas políticas, educativas, de comunicación, tecnología, religión, etcétera, actúan dentro de un mercado más abierto en el que las tecnologías ofrecen las herramientas que hacen posible esa comunicación. Algunos autores incluso sostienen que la sociedad del siglo XXI vivirá inmersa en una supranación de la que ya forma parte la sociedad actual.

Si se indaga en el transcurso de la civilización, la tecnología ha estado presente constantemente, en ocasiones de forma muy rudimentaria -primeros usos de la piedra o la rueda- y en otras muy sofisticadas -fusión del átomo-. Algunos historiadores ponen el punto de partida de la tecnología en los cambios que se produjeron en tiempos de la ilustración francesa y en el triunfo del positivismo, porque se valora la razón para juzgar cualquier proceso y ese trabajo implica una relación interdisciplinar entre las principales ciencias de entonces: las matemáticas, la física, la astronomía y la física. Se busca una 
aproximación más real de la ciencia a la humanidad, a lo que se dio en llamar las leyes universales con las que conviven las personas. Con posterioridad, a lo largo del siglo XIX, esos esquemas se rompen y esa ciencia que se plantea para mejorar las relaciones sociales, económicas y humanas, no fructifica; de ahí que aparezcan otras corrientes de opinión que consideran necesaria una sociedad más racional, justa y motivada. En el siglo XX la tecnología está marcada por las guerras, fundamentalmente las dos grandes guerras en Europa. Se empieza a valorar el conocimiento porque ayuda a resolver situaciones que implican llegar antes que el enemigo o saber cómo enfrentar la estrategia que propone el rival. Durante el siglo XXI se irán resolviendo los problemas tecnológicos para que la brecha digital disminuya. El futuro apunta a la introducción de la realidad virtual en la educación, -figura 4- según algunos expertos (Reinghold (1986), Lanier (1999).

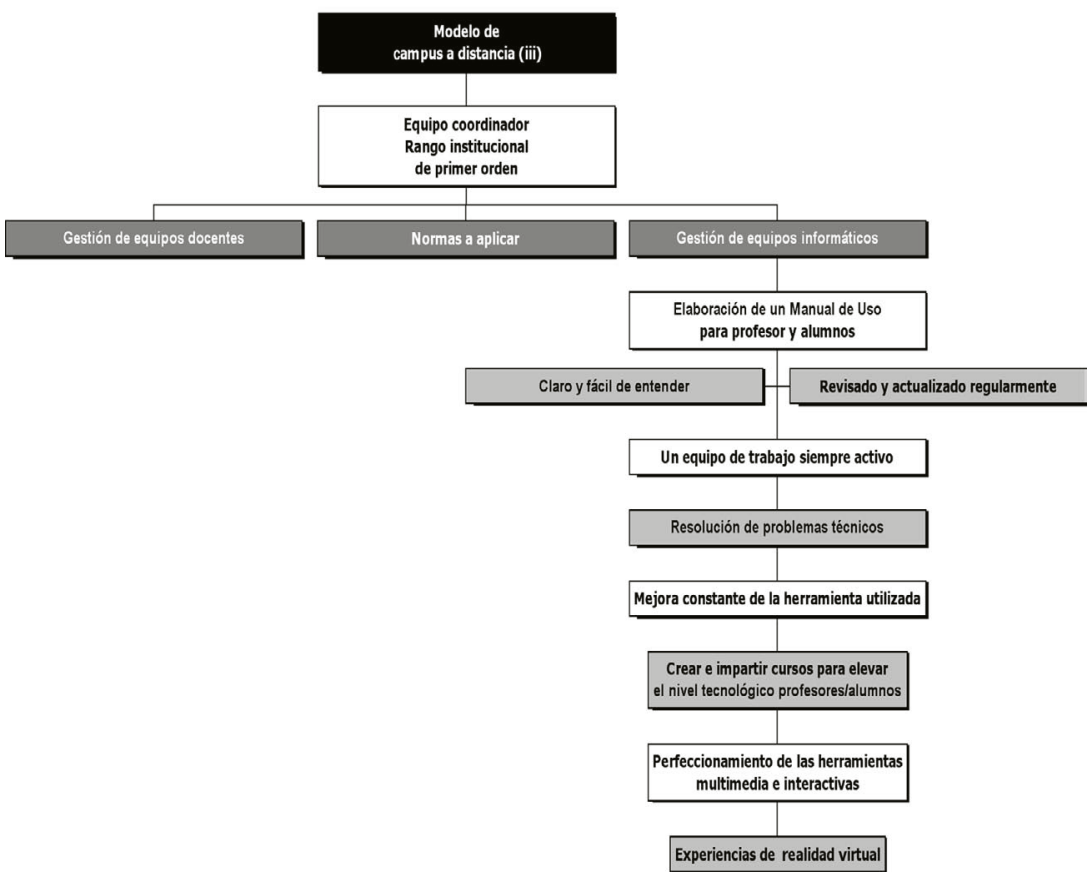

Figura 4. Control y mejora de las tecnologías para uso de la docencia a distancia

En la última década del siglo XX se produjo el gran avance, el despegue hacia otra forma de mostrar la docencia y la implicación con nuevas tareas para los alumnos y los profesores, quienes ahora empiezan a compartir recursos y a tener actividades fuera del horario y el ámbito educativo. Llegar a 
la situación actual ha sido posible gracias a una serie de ciclos o revoluciones que en sus orígenes son comunes para la mayoría de los teóricos, mientras que las cifras y las formas cambian cuando se trata de los soportes y el momento de su utilización. Lo normal han sido entre tres y cinco revoluciones, pero cada autor propone algunos aspectos diferenciales.

Fabio Chacón $(1996,1998)$ propone cuatro ciclos:

1er ciclo. Material escrito (cartas, correspondencia, etcétera): Algunos textos vienen acompañados de imágenes, pero no siempre llegan a tiempo y existe el riesgo de que desaparezcan. Existe una sola dirección: el alumno recibe el curso y lo estudia.

$2^{\circ}$ ciclo. Material escrito/sonoro: El proceso de envío sigue siendo por correspondencia pero las actuaciones educativas incluyen ya una comunicación entre el docente y el alumno. El teléfono sirve para resolver las dudas del estudiante y para hacer propuestas de trabajo entre profesor y alumno. Hay doble direccionalidad pero ésta es muy limitada.

3er ciclo. Materiales audiviosuales: Éstos se complementan con lo anterior, pero entran en acción otros medios de comunicación como la radio y la televisión. Cambian los métodos porque junto a la palabra impresa el alumno escucha y también ve lo que le explican: se mezcla el texto con las actividades multimedia. La dirección sigue siendo limitada y el teléfono es más utilizado que la carta; los actores son pasivos, reciben mucha información pero aportan poca.

$4^{\circ}$ ciclo: Materiales interactivos: Los sistemas de conexión en línea le sirven al docente para ofrecer contenidos educativos a distancia y al alumno para acceder a los mismos desde su casa o su trabajo. Aumenta la interactividad: correo electrónico, videoconferencia, chat, grupos de discusión, etcétera. Es posible la actualización diaria de contenidos y la presentación de prácticas, así como el intercambio de tareas entre estudiantes, y entre profesores y estudiantes. Se experimenta con sistemas móviles como el teléfono y otros que vendrán en el futuro. En esta etapa la reducción de costos es mayor, pues con una copia miles de alumnos pueden acceder al contenido.

Otros autores, entre ellos, Taylor, J. C. (2003) enumeran cinco generaciones. Más recientemente Anssi Vanjoki (2004), vicepresidente de Nokia, enuncia seis revoluciones desde la llegada del libro hasta la fecha actual: imprenta, radio, televisión, grabadoras de todo tipo, Internet y móviles. Es ese pequeño aparato, el teléfono móvil, el que más recursos está ofreciendo en el ámbito de la comunicación y una herramienta que ha sido estupendamente bien 
aceptada por las generaciones más jóvenes, de ahí la importancia de su uso para la educación.

\section{Propuesta de estándares educativos}

Llegados a este punto es necesario identificar qué es y para qué sirve un estándar educativo. Lo podríamos definir como un conjunto de reglas de uso común entre universidades que desean otorgar educación a distancia, siguiendo criterios previamente establecidos y respetados por todas las instituciones que manejen el mismo estándar. Si bien la mayoría de los programas informáticos tienen sus funciones cerradas, es decir no se pueden innovar otras, en el caso de la educación se ha pensado disponer de fórmulas amplias que le permiten luego a cada profesor obtener las que mejor se adapten a su asignatura. Lo que rompe un estándar educativo es implementar servicios de otras herramientas que luego dificultan el trabajo docente de cada día. Si lo que se persigue por parte de las universidades que imparten estos estudios es compartir recursos, aquellos que se empleen fuera del estándar no serán visibles para el resto de los miembros de esa comunidad. Por eso se crearán reglas que deberán especificar cómo se prepara la docencia y cuál será la plataforma sobre la que se realizará la actividad, de tal forma que se pueda interactuar con otras plataformas e intercambiar cursos, asignaturas y otros servicios. Si se siguen estas normas, diversas plataformas LMS (Learning Management Systems) podrían compartir datos, e incluso diferentes profesores de una misma área ofrecer sus trabajos dentro de un mismo programa de estudios.

Autores como Jorge Diéguez consideran que si no se aplica algún tipo de estándar en la educación, ésta pierde competitividad y calidad, aunque reconocen quienes ya están utilizando algunas herramientas que nunca habrá estándares que se adapten a las necesidades de cada profesor. "Los estándares deben aplicarse en la educación virtual por el mismo motivo que usamos la corriente $220 \mathrm{~V}$ en casi todas las redes del mundo" explica Diéguez. ${ }^{8}$

Algunas características de un sistema normalizado de enseñanza propuestas por Romero, Barale, Rinaldi ${ }^{9}$ (2004) son:

1. Durabilidad: que la tecnología desarrollada con el estándar evite la obsoletización de los cursos.

8 Jorge Diéguez, "Normativas y estándares para el tratamiento de contenidos”, en Estándares y especificaciones tecnológicas para el e-learning, Congreso Online Educa Madrid, 2004.

9 Daniel Romero; Juan Pablo Barale y Carlos Manuel Rinaldi, "Gateway para el reciclaje de sistemas e-learning que no cumplen con SORM", en Primer Congreso Virtual Latinoamericano de Educación a Distancia, 23 de marzo al 4 de abril de 2004. 
2. Interoperabilidad: que se pueda intercambiar información a través de una amplia variedad de LMS.

3. Accesibilidad: que se permita un seguimiento del comportamiento de los alumnos.

4. Reusabilidad: que los distintos cursos y objetos de aprendizaje puedan ser reutilizados con diferentes herramientas y en distintas plataformas.

A pesar de ese esfuerzo normalizador se hace necesaria una postura común entre los diversos órganos que crean estándares para que los sistemas avancen. El ejemplo más claro de la expansión de Internet no sólo está en la presentación multimedia que ofrecen las páginas web, sino en que previamente se acordó un estándar de comunicación, un protocolo conocido como TCP/IP que ha servido para que las computadoras de todo el mundo se puedan conectar de manera más fácil. Al final habrá que buscar un lenguaje común y unas especificaciones y estándares para aplicar en la mayoría de los casos, como propone Castellanos Coutiño: ${ }^{10}$

En e-learning, los metadatos describen e identifican los contenidos educativos para que puedan ser encontrados, ensamblados y enviados a las personas correctas y en el tiempo correcto. El contenido está siendo dividido constantemente en piezas pequeñas de información llamadas Learning Objects que son adaptadas a necesidades específicas. Los lenguajes utilizados por las organizaciones relacionadas con la estandarización son RDF, Dublin Core y principalmente el lenguaje de marcado XML.

Los estándares son necesarios, pero más importante es la voluntad, las ganas, las necesidades y la implicación que ponga el docente, así como el interés, participación y uso que ejerzan los estudiantes.

En este sentido, las principales propuestas de especificaciones llegan de fuera del ámbito educativo, pero en la mayoría de los casos la adaptación ha sido ejemplar. Las que más han aportado al desarrollo y la situación actual de la educación a distancia son:

1. Aviation Industry Computer Based Training Committee (AICC) que se inició en el campo de la aviación pero que ha traspasado ese ámbito y ofrece enseñanza a través de computadores.

10 Carlos Alberto Castellanos Coutiño, "Panorama general de los sistemas de educación a distancia”, ponencia en el Primer Congreso Virtual Latinoamericano de Educación a Distancia, LatinEduca 2004.com

http://www.ateneonline.net/datos/19_01_castellanos_carlos.pdf [Consultada: 04-05-2004]. 
2. Advanced Distributed Learning (ADL) del Departamento de Defensa de Estados Unidos que se diseñó para reutilizar las tecnologías militares en beneficio de la enseñanza.

3. Learning Technology Standards Committee (IEEE/LTSC), produce estándares abiertos de reconocido prestigio que luego se pueden aplicar en diversos campos.

4. Instructorial Management System Global Learning Consortium (IMS). Se trata de una institución sin ánimo de lucro que trabaja para el ámbito educativo y que desde comienzos del 2000 actúa como organismo independiente. No ofrece programas concretos sino que da normas para que sean desarrolladas. En este consorcio tienen intereses grandes empresas con presencia educativa como son Oracle, Microsoft, Apple, IBM o WebCT, entre otras.

Dentro de esta herramienta se configuran varios servicios; por citar algunos, en 2001 se creó IMS Learning Resources Meta-data Specifications, que permite generar recursos de aprendizaje de manera uniforme para que con posterioridad sean encontrados con rapidez; IMS Entreprise Specification, en 2002, que resuelve las situaciones administrativas que se producen al gestionar cursos y asignaturas en Internet, o el módulo que sirve para hacer exámenes y autoevaluación y que se conoce como IMS Question ETest Specification, en el 2002. Desde la creación de esta herramienta se le han ido introduciendo mejoras en función de las necesidades planteadas por los profesores y, sobre todo, por los alumnos.

5. Learning Management System (LMS): es un software para servidores de Internet e Intranet que realiza tres funciones básicas según Romero, Barale, Rinaldi, ${ }^{11}$ (2004):

1.- Gestionar los usuarios: inscripción, control de sus aprendizajes e historial, generación de informes, etcétera. Cuando el alumno hace su matrícula se le asigna un grupo con esta herramienta. El profesor, a su vez, dispone de listas de alumnos, por lo que no tiene que preparar sus fichas de control y seguimiento de los alumnos.

2.- Gestionar y lanzar los cursos así como realizar un registro de la actividad del usuario, de los resultados de los tests

11 Daniel Romero; Juan Pablo Barale y Carlos Manuel Rinaldi, "Gateway para el reciclaje de sistemas e-learning que no cumplen con SORM", en Primer Congreso Virtual Latinoamericano de Educación a Distancia, 23 de marzo al 4 de abril de 2004. 
y evaluaciones que se realicen, y del tiempo que se empleó y el acceso que se tuvo al material formativo.

3.- Gestionar los servicios de comunicación que son el apoyo al material en línea, y programar y ofrecerlos, conforme sean necesarios, foros de discusión, charlas y videoconferencias.

Si se cumplen estos requisitos el docente no tiene que modificar sus cursos y asignaturas cada vez que su universidad decide implementar una nueva herramienta. Simplemente tendrá que trasvasar el contenido.

Existen muchos LSM de distintos fabricantes y hay que lograr una norma que permita compatibilizarlos. Sin embargo algunas universidades han encontrado modelos de uso que aplican con suficientes garantías para el uso de alumnos y profesores. Al menos en una primera fase el rendimiento es aceptable. En el futuro podrán plantearse problemas cuando se quiera implementar este tipo de educación en otras universidades.

\section{De la EduCaCión CONTINUA a LA EDUCACión a DISTANCIA EN MÉxico}

La acelerada revolución que está experimentando la educación superior no es ajena a México, país que siempre ha tenido una inquietud (aunque sea a nivel de pequeños grupos o instituciones) por probar y estar a la vanguardia en la educación. Los antecedentes se sitúan a comienzos de los años setenta del siglo pasado, concretamente en 1972, cuando empieza a funcionar el Sistema de Universidad Abierta de México. Desde entonces hasta la fecha, las ideas de educación continua, educación abierta, educación constante han marcado parte de las actividades educativas. Los actuales estudios a distancia proponen precisamente esa forma de realizar la docencia, es decir, una actividad que no tiene horarios fijos sino que se desarrolla en función de las necesidades y disponibilidades del alumno.

La educación a distancia está pensada para los estudios superiores, pero al ser la interactividad una de sus características principales se le exige al alumno una formación previa personal y tecnológica para que pueda interactuar. En este sentido difiere de los programas educativos que se emiten para niveles inferiores y en los que el alumno aprende a través de la imagen pero no tiene opción de responder. La educación superior exige un esfuerzo de las instituciones para que éstas sean capaces de formar alumnos con capacidades creativas y con iniciativas dentro del mundo empresarial para que contribuyan a crear una sociedad más justa, tal y como se recoge en el 
Compendio de la Declaración Mundial sobre la Educación Superior de la UNESCO. $^{12}$

La pertinencia de la educación superior debe evaluarse en función de la adecuación entre lo que la sociedad espera de las instituciones y lo que éstas hacen. Para ello, las instituciones y los sistemas, en particular en sus relaciones aún más estrechas con el mundo del trabajo, deben fundar sus orientaciones a largo plazo en objetivos y necesidades sociales, y en particular el respeto de las culturas y la protección del medio ambiente. Fomentar el espíritu de empresa y las correspondientes capacidades e iniciativas ha de convertirse en una de las principales preocupaciones de la educación superior.

Aquí no se pretende ofrecer una historia de este tipo de estudios en México, sino recoger los avances producidos en los últimos años, es decir finales del pasado y los recientes del siglo XXI, en algunas universidades y centros de educación privados, y ver luego cómo han ido evolucionando en el ámbito bibliotecológico. Así se podrá analizar la situación actual y hacer predicciones sobre la implantación de estudios a distancia, y sobre el desarrollo y la evolución de algunos que ya llevan funcionando varios años. Es necesario mencionar el esfuerzo que están realizando instituciones como la Asociación Nacional de Universidades e Institutos de Educación Superior (ANUIES), ${ }^{13}$ con programas como la Educación Superior en el Siglo XXI. Líneas estratégicas de desarrollo. Una propuesta de la ANUIES donde se recogen las líneas maestras de actuación para las universidades, los profesores y los alumnos, que está respaldada por la Secretaría de Educación Pública (SEP) y la Universidad Nacional Autónoma de México (UNAM), entre otras universidades.

Retomando los comienzos, algunos autores (Vega García; ${ }^{14}$ De la Rosa Reyes, ${ }^{15}$ 2004) sostienen que el desarrollo educativo actual está buscando una nueva oportunidad formativa con el apoyo de las tecnologías como la fibra óptica, los satélites, la programación de televisión educativa, el uso del video bajo demanda o la utilización de las videoconferencias. La primera de las autoras hace un análisis de cómo ha ido cambiando la educación desde los años

12 UNESCO, "Compendio de la Declaración Mundial sobre la Educación Superior". http://www.unesco.org/education/educprog/wche/compendio.htm [Consultada: 10-06-2004].

13 Ver este estudio en el sitio oficial de ANUIES, sección Biblioteca digital: http://www.anuies.mx/index1024.html [Consultada: 10-06-2004]

14 Rosario Vega García, "Educación continua y capacitación a distancia en México", en Primer Congreso Virtual Latinoamericano de Educación a Distancia, 23 de marzo al 4 de abril de 2004. http:www.ateneonline.net/datos/99_01_Vega.pdf [Consultada: 12-05-2004].

15 María de los Ángeles De la Rosa Reyes, "El desarrollo de competencias comunicativas: uno de los principales retos en la Educación Superior a Distancia”, en Primer Congreso Virtual Latinoamericano de Educación a Distancia, 23 de marzo al 4 de abril de 2004. http:www.ateneonline.net/datos/25_03_De_la_Rosa-Angeles.pdf [Consultada: 12-05-2004]. 
setenta, cuando se apostó que la universidad sería el trampolín para formar a los grandes profesionistas que México necesitaba. Más tarde, en los ochenta, descendió la valoración y el título de licenciado de la educación superior perdió fuerza de cara al mercado. Se demandaba una mejor y mayor preparación, algo que en esos momentos no parecía ofrecer la universidad. Los años noventa tampoco aclararon el panorama pese a algunos esfuerzos que hizo el Gobierno. Vega García señala como principales problemas la masificación en las aulas, la baja calidad académica, la escasa flexibilidad y movilidad institucionales, el pobre financiamiento y un alejamiento de la educación superior frente a la sociedad, lo que permitió que nacieran universidades privadas con un fuerte dinamismo que atrajo a muchos estudiantes. Precisamente algunas universidades privadas aprovecharon ese vacío de calidad y ofrecieron programas de estudio competentes que las han convertido en punteras dentro de la educación y el campo profesional mexicano.

Por su parte De la Rosa apuesta por unos estudios basados en la competencia, entendida ésta como las actitudes y habilidades que deben desarrollar los profesores y los alumnos. Se trata en realidad de producir programas educativos que sean interactivos y aprovechar todos los recursos que ofrecen las tecnologías para que lleguen a una gran cantidad de alumnos, sobre todo en espacios geográficos tan grandes como los de México. La tan pronunciada frase aprender a aprender le sirve a esta autora para delimitar el objetivo y las responsabilidades de las universidades con la educación a distancia:

[...] la importancia de los sistemas educativos en general, y las universidades en particular -como centros de producción y circulación de conocimientos-, en la creación de las condiciones de posibilidad de alcanzar el nivel de sociedad del conocimiento, es que juegan un papel fundamental en la formación de los sujetos para que aprendan a aprender, a hacer un procesamiento crítico de la información a la que tienen acceso y a generar conocimiento. ${ }^{16}$

Para evaluar la educación a distancia en México hay que delimitar antes el proceso de educación continua y los intentos de mejora y capacitación desarrollados a lo largo del siglo XX. Hay que conocer también las estrategias políticas, porque éstas reflejan un esfuerzo que no siempre se traduce en apoyos financieros. Sin embargo, salvo en periodos de crisis social, los diferentes gobiernos mexicanos han mostrado casi siempre interés hacia este sector, muchas veces debido a la propia demanda del ámbito profesional, que requiere una mayor preparación para no tener que importar trabajadores cualificados. 
Ese apoyo institucional viene de lejos, tal y como señala García González, ${ }^{17}$ quien pone como fecha de partida el año de 1993, cuando la UNAM celebró las Primeras Jornadas Médicas.

Desde entonces cada año han surgido nuevas e interesante propuestas de este tipo que han cambiado sustancialmente en los últimos tiempos con la implantación de tecnologías que permiten una interactividad entre el profesor y el alumno. En este sentido, hay que señalar que sin ese esfuerzo de educación continua, de educación abierta, por dar más posibilidades para que todos los mexicanos tengan acceso a la educación superior, implementar ahora estudios a distancia utilizando la tecnología implicaría más tiempo y más recursos. Por lo tanto, se habrá de experimentar un cambio que implique desarrollos tecnológicos, pero quizá no sea traumático para las universidades si éstas aprovechan algunos de los recursos que se utilizaron en la educación continua. Al final surgirá un nuevo sistema de aprendizaje, pero para hacer este trasvase los estudios superiores mexicanos tienen suficientes experiencias y quizá no tengan que hacer cambios radicales, al menos en algunas disciplinas.

¿Cómo se tiene que hacer?, ¿cuánto tiempo va a durar?, ¿quién ha de financiar esta transformación?. Las respuestas son muchas y diversificadas porque afectan a toda la sociedad. La implantación de los estudios a distancia será gradual, y en ella las instituciones asumirán el papel protagonista, y gestionarán y colaborarán con los profesores para que hagan un primer esfuerzo frente a los alumnos. A éstos se les pedirá un compromiso mayor porque todas esas inversiones se harán para que el alumno pueda hacer estudios superiores al mismo tiempo que trabaja.

En el ámbito privado son ya muchas las universidades e instituciones que ofrecen educación superior a distancia. Pionero fue el Instituto Tecnológico de Estudios Superiores de Monterrey que desde hace quince años está desarrollando tecnologías educativas a distancia en diversas licenciaturas. Este instituto cuenta con 33 campus en 20 estados de la República y ofrece programas para todo el continente, y dispone de una Universidad Virtual que imparte educación de calidad. Además ha formado ya una comunidad educativa que tiene influencia internacional. Esta institución se ha convertido en la más importante en el uso de la tecnología, aplica diversos sistemas y experimenta nuevas formas. En el ITESM se pueden hacer estudios combinando recursos como la televisión, el satélite, el video bajo demanda y, por supuesto, Internet. Para dar servicio a una comunidad de mas de 80.000 alumnos en todo el continente, el instituto ha creado, a través de la educación a distancia,

17 Eva Laura García González, Gestión de la educación superior continua y la capacitación, Manual moderno, 2004. 
herramientas de apoyo como bibliotecas digitales y tutores académicos que atienden las necesidades reales de los alumnos. Al contrario que en algunas universidades públicas, donde el profesor es quien hace todas las gestiones; en el ITESM, en función del número de alumnos, el profesor cuenta con ayudantes y tutores. Pero no se trata de acciones aisladas, como ha sucedido en universidades europeas, sino de todo un conjunto en el que están implicadas diversas áreas y departamentos.

Otra institución que ha desarrollado planes de formación a distancia es el Instituto Latinoamericano de Comunicación Educativa (ILCE) que tiene como misión potenciar el uso de las tecnologías de información y comunicación, y ayudar al desarrollo y superación de las personas de manera integral, fomentando la cooperación, el trabajo y la formación a distancia (flexibilidad de tiempo y espacio), y disminuyendo y optimizando los costos ofreciéndoles soluciones oportunas a sus clientes y usuarios. Entre sus proyectos más actuales figura la puesta en marcha del Centro Interactivo Multitecnológico de Educación a Distancia (CIMED) cuyo fin, según Rosario Freixas, ${ }^{18}$ directora académica, es: "[...] dar capacitación a servidores públicos en diferentes plataformas y basados en objetos de aprendizaje con las normas internacionales SCORM y ADL”. Esa opinión se suma a la expuesta en este artículo, que reitera la necesidad de usar normas internacionales que permitan compartir experiencias y no duplicar las acciones formativas. De similares características es el Instituto Autónomo de México (ITAM), que en colaboración con Canacintra-Satelital ${ }^{19}$ ofrece cursos vía satélite para más de 50 ciudades del país, y que en la actualidad trabaja para presentar un software educativo propio que le permitirá ofrecerles a los alumnos un diploma interactivo. Además, se propone que el alumno pueda utilizar las computadoras en sistemas de tutoría a distancia.

De los numerosos centros que imparten ya educación superior a distancia, referenciaré uno de los últimos en llegar: la Universidad Tecnológica de México (UNITEC) que está adaptando estos estudios para el desarrollo profesional diversificado mediante cursos, seminarios y jornadas que sirven para preparar los temas educativos interactivos en línea, lo que luego se ofrecerá en las licenciaturas. Esto se hace a través de la "incubadora de empresas" ${ }^{20}$ que consiste en

18 Rosario Freixas Flores, "Hay que compartir experiencias y dejar de duplicar esfuerzos”, en Elearning America Latina, Entrevista publicada en el número 3, año 2, 10 de septiembre de 2004. http://www.elearningamericalatina.com/edicionseptiembre1_2004/tr_1.php [Consultada: 10-09-2004].

19 "La experiencia de Educación en Línea de México", en Instituto de Financiamiento e Información para la Educación (EDUCAFIN). http://www.educafin.com/editorial.htm [Consultada: 10-06-2004].

20 Ver sitio oficial de esta Universidad. http://www.unitec.mx/Incubadora/index.html [Consultada:3-06-2004]. 
[...] un conjunto de recursos que apoyan a un equipo de personas emprendedoras en la creación de una empresa basada en una idea de negocio innovadora y con factibilidad de éxito en el mercado. Una incubadora especializada en negocios electrónicos está orientada a la generación de negocios para los cuales la tecnología de Internet es un componente fundamental.

En el ámbito público, la mayoría de las universidades ya tiene alguna experiencia en la implantación de estudios en línea, aunque sea a nivel de casos prácticos realizados por algún profesor. Asimismo se han creado centros para que las estrategias sean comunes en las diferentes instancias educativas, como el Centro de Coordinación de Universidad Abierta y Educación a Distancia. Es necesario indicar que se deben coordinar acciones desde un principio para evitar repeticiones de contenidos y duplicar prácticas o actividades solapadas que no le aportan nada a la educación.

\section{Propuestas globales de educación a distancia en la UNAM}

La Universidad Nacional Autónoma de México (UNAM) ha tenido siempre una inquietud, un espíritu abierto para mejorar la educación, y su constatación más importante se refleja en los numerosos centros que ha creado para darles opciones a todos los mexicanos que quieren acceder a una cultura superior. Hace esto a través de la educación presencial en sus aulas; creando y gestionando un sistema de universidad abierta; dando facilidades para que los alumnos opten a estudios de educación a distancia, y amparando y gestionando programas de educación continua. Estas actuaciones no son fruto de una casualidad o de una moda reciente por el consumo tecnológico. Ya en la década de los cincuenta del siglo pasado, la UNAM utilizó la tecnología de entonces para ofrecer su trabajo. Primero fue por medio de la radio, luego creando programas para la televisión y, más adelante, con el uso del video, que permitía grabar y repetir los productos educativos en función de las necesidades de los alumnos.

Se hizo necesario, entonces, un avance mayor. El video y la televisión son sistemas cerrados que permiten una actualización con base en mucho trabajo. La llegada de los satélites abrió la transmisión hacia comunidades alejadas geográficamente, pero aún se mostró esto como insuficiente. Entonces llegaron las computadoras para darle un vuelco al trabajo docente. En los comienzos se continuó utilizando soportes cerrados como el CD-ROM, que mejoraba las capacidades de texto e imágenes pero que presentaba un problema: su actualización. Se necesitaban varios discos compactos para ofrecer una sola materia educativa. A pesar de la interactividad que ofrecían -un avance con 
respecto al soporte papel- no fue suficiente para el desarrollo normal de una asignatura, lo cual necesitaría manejar datos recientes y actuales.

Llegaron entonces los sistemas en línea y revolucionaron la forma de trabajar, enseñar y hasta vivir. Las redes digitales ofrecían conexión a millones de computadoras situadas en los límites más insospechados. La educación aprovechó estos recursos para crear y transmitir cursos, videoconferencias, jornadas y actos puntuales. Más tarde se produjo un avance más significativo, cuando algunas universidades deciden colocar asignaturas para que los alumnos las tomen presencialmente a distancia o en un sistema mixto. Ciertas propuestas docentes del ámbito de la tecnología, sobre todo facultades de informática, ingeniería y disciplinas científicas, sirvieron para convencer a los equipos rectores de las universidades para que tomaran una decisión común sobre un proyecto institucional educativo a distancia, basado en alguna de las propuestas internacionales que permiten la cooperación con otras instituciones.

En el caso de la UNAM, el último Catálogo de Educación a Distancia recoge las actividades de 29 instituciones universitarias que dieron a conocer sus actividades en este ámbito. En total este catálogo incluye 383 cursos, diplomados, talleres y seminarios, 81 de los cuales se hacen a través de Internet; 244 en video; 42 en CD ROM y otros con varias combinaciones de estos elementos. Otros recursos empleados son la videoconferencia, que se graba y luego se puede ver en Internet; revistas y libros en la red y diversos portales temáticos. También como uso alternativo, el catálogo recoge otros soportes didácticos como la radio y la televisión, hasta alcanzar un total de 1062 materiales. Entre los 29 diferentes participantes se encuentran la Facultad de Filosofía y Letras y el Centro Universitario de Investigaciones Bibliotecológicas.

México está considerado dentro de América Latina como el país que más aportaciones realiza dentro de la educación abierta y a distancia, gracias al trabajo desarrollado por la Secretaría de Educación Pública (SEP) y la Universidad Nacional Autónoma de México (UNAM), entre otras instituciones de educación superior.

\section{Coordinación de la Universidad Abierta y la Educación a Distancia (CUAED)}

El organismo encargado de la educación abierta y a distancia en la UNAM es el centro de Coordinación de Universidad Abierta y Educación a Distancia (CUAED), institución que trabaja para hacer la educación más flexible, dinámica y de calidad. Otro objetivo importante es atender las necesidades personales de los estudiantes en materia educativa. Entre sus actividades destacan la 
[...]divulgación de las prácticas de educación del Sistema Universidad Abierta, Continua y a Distancia más adecuadas, así como el impulso a los mejores usos educativos de la tecnología que resultan de su actividad de prospección y producción de materiales. Su tarea también radica en difundir los métodos de evaluación, acreditación y certificación de conocimientos; colaborar con las entidades universitarias para su óptima integración en Educación Abierta, Continua y a Distancia y, responder a las necesidades de educación y capacitación de instituciones educativas, sociales, gubernamentales y empresas privadas a fin de llevar la Universidad a las diferentes organizaciones que la requieran, sean éstas nacionales o internacionales. ${ }^{21}$

Aquí se mencionan sus diversos campos de actuación, entre los que figura, como dato significativo, dar un servicio óptimo a las universidades en los estudios a distancia, pero también hacer su evaluación y certificación, tan necesitada en estos estudios que han ido apareciendo a veces sin control por parte de las universidades.

El Sistema Universidad Abierta (SUA), ${ }^{22}$ creado el 16 de febrero de 1972, formaliza sus trabajos para ofrecer materiales didácticos, y fórmulas para aplicar y evaluar en los sistemas de aprendizaje el uso de los medios de comunicación y diferentes estructuras de gestión, todo ello con el fin de mejorar y diversificar los materiales didácticos. Como se señala en su página web, pretende

[...] extender la educación universitaria a grandes sectores de la población por medio de métodos teórico-prácticos de transmisión y evaluación de conocimientos y de la creación de grupos de aprendizaje que trabajarán dentro o fuera de los planteles universitarios.

Su principal objetivo es facilitarles a los estudiantes "[...]la posibilidad de combinar el estudio con el trabajo, mediante la flexibilidad de horarios y la adaptación personal a ritmos y métodos de aprendizaje". Su campo de actuación son las carreras de contaduría, administración e informática. Esta experiencia, ya lejana en el tiempo, orienta sobre una de las necesidades básicas de los estudios actuales: la falta de tiempo, o la imposibilidad de desplazarse hasta los centros educativos. Con este sistema se les daba opción a los alumnos para que a través de métodos alternativos se evaluaran y adquirieran conocimientos.

21 Fuente: página web CUAED. http://www.cuaed.unam.mx/contenido/notices.htm [Consultada: 11-06-2004]

22 Fuente: página web SUA http://fcasua.contad.unam.mx/sua/que_sua.htm [Consultada: 11-06-2004] 
Otro avance significativo se produjo con el apoyo a la educación a distancia. En sus orígenes a través de un sistema de telecampus y la aplicación de una normatividad que hiciera posible una educación abierta, presencial y continua, y que contemplara a su vez la formación de profesores y el desarrollo del proyecto para una universidad en línea. La CUAED participó ampliamente en programas de apoyo a EDUSAT, lo que implicó que más de quince mil alumnos tuvieran acceso a estos programas. Por su parte la educación continua sigue realizando cursos, talleres, seminarios y diplomados con alta participación, un total de más de 125.000 alumnos por año.

Sin embargo el avance más reciente y significativo del CUAED se produce a comienzos del siglo presente, cuando se le da un impulso a la educación a distancia y se establecen relaciones con instituciones y universidades de otros países, además de que se fomenta el uso de las tecnologías a través de congresos; así, el Virtual Educa 2005 se celebró en la UNAM. Experto en la educación a distancia, Berruecos Villalobos ha manifestado en diversas ocasiones que existe ya un respaldo hacia este tipo de educación en algunas universidades mexicanas, entre las que destaca la propia UNAM, la Universidad de Guadalajara, la de Nuevo León, el Instituto Tecnológico de Monterrey, etcétera.

Berruecos propone como método de trabajo para avanzar en este tipo de educación una serie de colaboraciones entre los países latinoamericanos, a saber:

1. Preparar personal que pueda organizar cursos, que conozca el diseño y que introduzca contenidos. Será importante vigilar esos contenidos para ofrecer información de calidad.

2. Algunos cursos serán presenciales, pero se ofrecerá una versión en línea.

3. Desde la UNAM se lanzarán luego programas de apoyo a otras universidades de América Latina.

4. El e-learning puede ser un medio de unión entras las naciones. ${ }^{23}$

La aplicación de estas actividades se debe realizar dentro de un marco global, con la universidad como referencia. Se piensa desde hace años en mostrar alternativas a la educación presencial que acoge cerca de 240.000 alumnos en la UNAM, sobre todo porque se ha comprobado que ciertas materias básicas han tenido una excelente acogida por parte de los alumnos.

El desarrollo de las tecnologías y las inversiones necesarias enfrenta a las instituciones educativas que demandan más recursos ante el problema de la

23 José Manuel Berruecos Villalobos, "Crece el respaldo a la educación virtual desde las universidades", en E-learning la revista digital de América Latina.

http://www.elearningamericalatina.com/edicion/agosto2/tr_1.php [Consultada: 27-05-2004]. 
llamada brecha digital con los países más desarrollados. A juicio de Berruecos Villalobos, México está haciendo un esfuerzo en este sentido:

Hay un programa gubernamental que tiene planeado abrir en todo el territorio mexicano cerca de 20.000 centros comunitarios con computadoras, a disposición del público. La idea es que en pueblos o ciudades con más de 3.000 habitantes exista al menos un centro con 20 computadoras. ${ }^{24}$

Sin embargo, la gran mayoría de los analistas de este tipo de estudios valoran más la formación personal, la introducción de los contenidos y la buena voluntad de los estudiantes, que la presencia de computadoras, ya que, aunque necesarias, en ocasiones han de ofrecer algo más que la simple máquina.

La propia UNAM fomenta cursos de capacitación en línea para profesores $^{25}$ a través del Sistema Programa Universidad en Línea (PUEL) ${ }^{26}$ Se trata de cursos de unas 30 horas en donde el profesor aprende a manejar herramientas y a trabajar en foros no moderados, para lo que también dispone de un asesor a través del correo electrónico. Una vez que el docente adquiere los elementos básicos puede completar y preparar cursos en línea a través del Taller Planeación Didáctica para cursos en línea, ${ }^{27}$ cuyo propósito es

[...]proporcionar a los participantes los elementos didácticos que les permitan planear, diseñar y poner en marcha programas educativos en línea, apoyados en las principales herramientas de Internet

Desde ese momento, el docente tiene conocimientos suficientes para poner su docencia en línea.

\section{Centro de Alta Tecnología de Educación a Distancia (CATED)}

Pero la institución dentro de la UNAM que habrá de impulsar el gran desarrollo de la educación a distancia es el Centro de Alta Tecnología de Educación a Distancia, el CATED, situado en Tlaxcala. En el acto de inauguración, el rector de la UNAM, Juan Ramón de la Fuente, señaló que este centro se creaba para responder a las necesidades educativas de carácter superior de México, y además precisó la importancia que el CATED tiene para el estudio a distancia, el cual se compartirá con los sistemas tradicionales:

24 Ibidem.http://www.elearningamericalatina.com/edicion/agosto2/tr_1.php [Consultada: 2705-2004].

25 Cfr.: http://www.puel.unam.mx/cursos/c_intro/index.htm [Consultada: 14-06-2004]. 
El CATED ha de ser visto como un polo educativo a nivel continental. No reemplazará a las universidades sino las enriquecerá. Su moderna tecnología tampoco sustituirá el binomio maestro-alumnos, más bien lo complementará. ${ }^{28}$

Este centro se creó con el objetivo de promover la tecnología más avanzada en el ámbito de la educación abierta, continua y a distancia, y recoge de este modo los tres sistemas que habrán de integrar una educación de calidad. La idea del centro es ofrecer este tipo de estudios a lo alumnos de la UNAM, pero se ha pensado desde un primer momento en ampliarlo a otras instituciones en el marco de la educación superior. En ese mismo acto, la secretaría de Desarrollo Institucional, Rosaura Ruiz Gutiérrez, precisó que se avanza con este centro en la creación de la "universidad en línea", a la que habrá que añadir el mayor número de licenciaturas y postgrados. Los primeros esfuerzos se dirigen hacia las carreras y programas de posgrado en humanidades y ciencias sociales porque son más fáciles de implementar ya que el alumno puede completar sus estudios en línea, mientras que las carreras técnicas que necesitan prácticas de laboratorio entrarán en una segunda fase. Un aspecto significativo en las carreras experimentales pasa por colocar la teoría en línea, pero las prácticas se harán en otras universidades mexicanas o fuera del país, por eso Rosaura Ruiz Gutiérrez precisó que éste es un "modelo de formación conjunta” que se ejecutará entre varias universidades. Aquí se refleja un aspecto fundamental de los estudios a distancia. Los recursos se comparten y los exámenes prácticos se pueden tomar en una universidad alejada físicamente de la ciudad o el país en el que vive el estudiante. Los títulos serán, en ese sentido, impartidos por una, dos o varias universidades. Esa es la gran aportación al mundo globalizado.

Desde el CATED ya se controlan algunas asignaturas que están en línea, pero se espera que en breve se amplíe la oferta educativa de esta modalidad para reducir las tasas de rezago y deserción de muchos alumnos universitarios. En aquellas asignaturas que se produzcan esos bajos rendimientos, se aplicarán primero estos programas a distancia. En todo caso, justifica Ruiz Gutiérrez $^{29}$ se pretende que el ciclo de educación a distancia sea completo.

El proyecto permitirá que el alumno pueda realizar desde su propia inscripción en la computadora. Tomará clases en casa o donde tenga acceso a la red; presentará

28 M. Álvarez, "Inaugura el rector trascendente Centro de Alta Tecnología de Educación a Distancia (CATED)"

http://www.elearningworkshops.com/modules.php?name=News \&file $=$ article $\&$ sid $=106$ [Consultada: 27-05-2004]

29 M. Álvarez, "Con clases en línea, ampliará la UNAM su oferta educativa a distancia". http://www.elearningworkshops.com/modules.php? name $=$ News \&file $=$ article $\&$ sid $=207$ [Consultada: 28-05-2004] 
los exámenes por la misma vía y tendrá el apoyo de un tutor, con el cual se comunicará por medio de la página electrónica.

Para llevar a cabo esta tarea la Secretaría de Desarrollo contará con el apoyo de varias Direcciones Generales: la de Estudios de Posgrado; la de Evaluación Educativa; la de Bibliotecas; la de Coordinación de la Universidad Abierta y Educación a Distancia, y la del Centro de Estudios para Extranjeros. A estas instituciones se les pedirá apoyo para crear y fomentar estudios a distancia.

\section{RECURSOS EDUCATIVOS EN ESPAÑA: MODELOS DE APLICACIÓN EN ALGUNAS UNIVERSIDADES}

Toda actividad educativa que se quiera realizar en línea precisa del trabajo colectivo de una universidad, un departamento o un grupo de profesores. Lo que se ha hecho hasta ahora responde a necesidades, inquietudes o avatares de un docente por ofrecer, a título personal, algunos contenidos en Internet. El punto de partida de muchas universidades no ha contado con un apoyo institucional, ha sido más bien el tesón de los profesores lo que ha obligado a la institución a aportar los recursos para crear la docencia en línea. Sin embargo una asignatura en línea, que suele ser el punto de partida y el campo de actuación de un profesor, un curso en línea como entidad menor, o un programa global de una institución, se crean siempre en torno a varias personas; a saber, uno o varios docentes, además de los moderadores; es decir, personas que no imparten clase pero que vigilan y ayudan a cumplir una asignatura: gestores de contenidos que se encargan de mejorar las propuestas educativas una vez que han sido ofrecidas por los docentes y el resto del equipo; uno o varios técnicos informáticos atentos a las propuestas del colectivo para convertir las ideas del grupo en una realidad manejable para profesores y alumnos y, en último lugar, un buen equipo de diseño que se encargará de que ese lugar de Internet sea atractivo para quien lo visita.

Los responsables de algunas instituciones educativas intentan mejorar con cada curso sus planes de estudios, y cada cierto tiempo se lleva a cabo un cambio significativo. Sin embargo en los últimos tiempos esto no es suficiente debido a que los alumnos demandan cada vez mejor calidad en los estudios y mayores salidas profesionales, lo que obliga a las universidades y centros docentes a mejorar su enseñanza y los lleva a considerar que el uso y apoyo de las tecnologías es una ayuda necesaria. Sin embargo estos organismos siguen conservándose muy estáticos frente a una tecnología que avanza 
significativamente. Los cambios se dan en todos los niveles y no sólo en la actitud y desarrollo del docente sino también en los equipos de gobierno que deben invertir en tecnología para que su institución sea más competitiva. Pero quizá de esta forma se garanticen las inversiones en educación, ya que una vez creados los cursos se pueden trasvasar de un sistema a otro, lo que a su vez permite crear más y dar acceso al campus a alumnos que hasta entonces no encontraban estos contenidos en un lugar a distancia.

Las instituciones están adaptándose y generando ya algunas orientaciones de cómo han de ser los alumnos y como han de actuar los profesores. Conscientes de que la evolución deberá ser medida y equilibrada, y no buscar cambios dramáticos, los dos actores principales están acercándose tímidamente a las propuestas institucionales. Habrá que mejorar las situaciones de grupos docentes muy numerosos, lograr un mayor número de prácticas y darle más tiempo a la investigación. De la misma opinión es el rector de la Universidad Complutense, Carlos Berzosa, ${ }^{30}$ quien explica cómo se está preparando esta universidad ante el Espacio Europeo de Educación Superior:

Para nosotros, la adaptación supone que haya menos alumnos por grupo y que haya más profesores, porque tenemos todavía una relación alumno/profesor muy alta comparada con el resto de Europa. Este cambio tiene que servir para facilitar la formación práctica. Creo que el alumno es muy pasivo en la enseñanza, se le da poco juego, hace pocos trabajos, tiene poca capacidad de exponer en clase, le cuesta mucho exponer en público, y éste es uno de los déficit que tenemos respecto a otros países. Hemos llegado a la clase de los apuntes en la que el alumno apenas si estudia los manuales. El alumno tiene que leer libros, tiene que participar en clase, tiene que acostumbrarse a exponer en público y tiene que ser un agente activo en la docencia y el aprendizaje.

Dentro de las instituciones están los profesores que a título personal y sin apenas reconocimiento académico y económico apuestan por mejorar su docencia introduciendo una parte de sus contenidos, prácticas y evaluaciones a través de Internet. Es necesario un mayor apoyo no sólo en recursos sino en motivaciones para que estos docentes sigan con su esfuerzo por acercar al alumno a otras formas de trabajar y estudiar.

Algunas universidades españolas ya dieron sus primeros pasos hacia el desarrollo de este tipo de herramientas. Dos ejemplos servirán para mostrar su implantación y los primeros resultados obtenidos: Universidad Complutense de Madrid (UCM) y Universidad Pablo de Olavide, de Sevilla.

30 Carlos Berzosa, "El estado de la educación superior".

http://aula.elmundo.es/aula/especiales/2004/50carreras/analisis.html [Consultada: 09-06-2004] 
En la UCM la herramienta informática que gestiona la educación en la red se conoce como Course Management System (CMS) y su soporte es WebCT. Los servicios son de tres tipos:

1. Alumnos: fichas de clase y listas. El profesor recibe su asignatura con un listado completo de los alumnos inscritos. La herramienta es muy sencilla de usar para el alumno.

2. Profesor: (creador de contenido y de los cursos) organiza grupos de trabajo con los alumnos. Recoge dentro de la asignatura sus trabajos y prácticas. Mejora la comunicación profesor-alumno, o alumno con otros alumnos y a su vez entre diversos profesores que estén colaborando o que tengan asignaturas parecidas. El profesor puede proponer controles, pruebas y exámenes más objetivos, y autoevaluación para que los alumnos se examinen. En definitiva, se concibe el sitio como un lugar para la organización de todos los recursos didácticos que propone el profesor, desde su publicación hasta los comentarios de los alumnos y una distribución más clara con respecto a los contenidos. La UCM seguirá las recomendaciones y estándares internacionales propuestos por W3C, IEEE-LTSC,(Learning Technology Standards Comité) IMS (Institutional Management System) y otras que se vayan creando con el fin de garantizar el funcionamiento de las actividades docentes en línea y su operabilidad entre las distintas facultades y futuros acuerdos con otras universidades.

3. Administrador de la plataforma: determina las categorías y los cursos. Implementa la herramienta de acuerdo con los estándares internacionales y con las necesidades de su propia universidad.

Esta herramienta, Figura 5 (a continuación), ofrece una flexibilidad y requiere una gran autodisciplina y organización por parte del alumno. Al profesor se le exige una adecuada planificación para aprovechar al máximo los recursos con los que cuenta. En la guía psicopedagógica de WebCT, puesta a disposición de los profesores por la Oficina de Cooperación Universitaria, se valora de forma considerable al alumno a quien no hay que considerar como un mero receptor de la información. Se le pide, sobre todo, que "[...] él mismo sea quien busque la información y construya conocimiento".

Las principales funciones con las que cuenta el profesor son:

1. Cronograma: que permite hacer un seguimiento temporal de todas las actividades, como pueden ser los foros, las videoconferencias o las evaluaciones, entre otras. 
2. Sistemas de evaluación en función del desarrollo del curso.

3. Bibliografía: libros y revistas, tanto básicos como complementarios, pero también sitios web y recursos dentro de Internet.

4. Otros recursos: desde el programa de la asignatura hasta el correo del profesor o jornadas que amplían los contenidos que facilita el profesor.

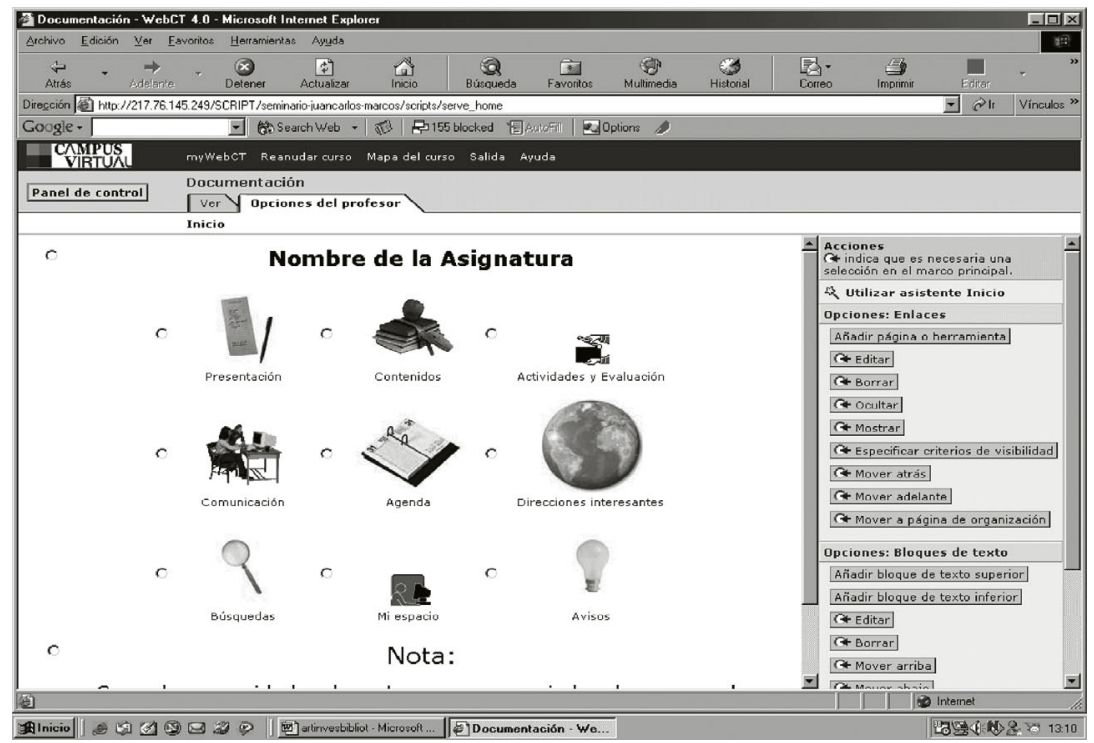

Figura 5. Las funciones del campus virtual de la UCM son comunes a las de otras universidades ya que emplea WebCT

Por su parte, el alumno accede a:

1. Foros o debates asíncronos para poner en común ideas desarrolladas en clase o para precisar o ampliar alguna de ellas.

2. Empleo de chats para comunicarse de forma síncrona. Se propone un tema y se debate entre todos los alumnos. Se debe pactar un tiempo y no excederse de él. Luego se puede continuar, distendidamente, en las llamadas "cafeterías virtuales", sitios de encuentro a los que los alumnos entran con posterioridad para compartir y debatir temas.

3. Uso de correo electrónico: como herramienta para comunicar cuestiones inmediatas. Los trabajos y las prácticas se depositan directamente en el espacio del profesor. Dos recomendaciones de los expertos de WebCT, convocar a los alumnos con tiempo suficiente y recordárselo el día anterior, y no excederse de dos horas. 
4. Pizarra compartida para el empleo de recursos gráficos. Se complementa con las actividades realizadas en un chat.

En mayo de 2004 se celebró la 1ª Jornada Campus Virtual UCM: "En apoyo del aprendizaje en la universidad, hacia el espacio europeo de educación superior", en la que se presentó el balance del primer año de actividad docente virtual en facultades y escuelas a través de varias ponencias. Los resultados más destacados de este primer año a nivel virtual en UCM son los que figuran en la Tabla I, de los que se destaca que el 66\% de los alumnos inscritos en el campus virtual participó de forma activa:

Tabla I: Aula Virtual UCM; ${ }^{31}$

\begin{tabular}{|l|l|}
\hline \multicolumn{1}{|c|}{ Curso 2003-04 } & \multicolumn{1}{c|}{ Datos globales } \\
\hline Alumnos & +3.500 \\
\hline Profesores & 200 \\
\hline Asignaturas & 91 (61 primer ciclo y 21 tercer ciclo) \\
\hline Promedio de entradas al CV & 147 (alumnos que han participado) \\
\hline 3 cursos de formación continua & +5 títulos propios \\
\hline
\end{tabular}

Tabla II: Balance primer año de actividad del campus virtual UCM

\begin{tabular}{|l|l|}
\hline \multicolumn{1}{|c|}{ Curso 2004-05 } & \multicolumn{1}{c|}{ Previsiones } \\
\hline Alumnos & Licencias ilimitadas \\
\hline Profesores & Todos los que opten por solicitarlo \\
\hline Asignaturas & Seminario virtual/Asignatura con fichas \\
\hline Seminarios de Formación & Colaboración con los coordinadores \\
\hline Colaboración con grupos de trabajo & + Investigación de la UCM \\
\hline
\end{tabular}

Es previsible que para el curso 2004-05 el crecimiento de asignaturas y alumnos aumente, puesto que además se han introducido mejoras que le facilitan el trabajo al profesor, como el no tener que introducir la ficha de sus alumnos, pues será la propia universidad la que ofrezca el grupo ya constituido. No habrá límite, como sucedió en el curso pasado, de tal forma que podrán solicitar el curso todos los profesores que lo pidan. En este sentido, el rector de esta universidad, Carlos Berzosa anunció que durante el curso 2004-2005 la universidad impartirá 280 asignaturas en la Red. El Campus Virtual UCM, mediante la herramienta de gestión de cursos WebCT, permitirá el seguimiento de los alumnos, la evaluación de los mismos, la comunicación -tutorías, correo electrónico interno, foros de debate, chats y

31 Fuente: $1^{\text {a }}$ Jornada Campus Virtual UCM

http://www.ucm.es/campusvirtual [Consultada: 02-06-2004]. 
pizarra compartida-, y la organización y la publicación de contenidos. Con esta iniciativa se pretende tener una herramienta de apoyo a la docencia, concebida para facilitar el trabajo de profesores y alumnos, y la transición al nuevo modelo de enseñanza europeo.

Por su parte, otra institución española, la Universidad Pablo de Olavide, en Sevilla, dispone desde hace ya tres cursos de una plataforma de teleinformación WebcT. A modo de resumen, el curso 2003-04 contó con 137 asignaturas; es decir, un 40\% más que el anterior, lo que significa que casi la mitad del personal ya usa esta plataforma WebCT en sus asignaturas. Con respecto a los alumnos, cabe indicar que el 95\% de los del primero y segundo ciclo usan esta herramienta como apoyo a sus estudios. En la tabla III se aprecia el incremento de asignaturas del curso 2002-03 al 2003-04.

Tabla III: Balance del curso 2003-04 e incremento con respecto al año anterior. Asignaturas dadas de alta en WebCT (por titulación) ${ }^{32}$

\begin{tabular}{|l|l|l|}
\hline \multicolumn{1}{|c|}{ U. Pablo de Olavide } & \multicolumn{1}{c|}{$\begin{array}{c}\text { Curso } 2003-04 \\
\text { Increm. }\end{array}$} \\
\hline Asignaturas de Libre Configuración & 6 & $50 \%$ \\
\hline Diplomatura en Ciencias Empresariales & 14 & $29 \%$ \\
\hline Lic. Derecho & 12 & $58 \%$ \\
\hline Dip. Relaciones Laborales & 7 & $29 \%$ \\
\hline Dip. Trabajo Social & 6 & $17 \%$ \\
\hline Dip. Educación Social (Nueva Titulación) & 5 & $100 \%$ \\
\hline Dip. Conjunta Ed. Social y Trab. Social (N. Titulación) & 3 & $100 \%$ \\
\hline Licenciatura en Ciencias del Trabajo (nueva Titulación) & 2 & $100 \%$ \\
\hline Lic. Administración y Dirección de Empresas & 23 & $39 \%$ \\
\hline Lic. Ciencias Ambientales & 40 & $28 \%$ \\
\hline Lic. Humanidades & 22 & $68 \%$ \\
\hline Lic. Conjuntas en Empresariales y Rel. Laborales & 3 & $33 \%$ \\
\hline Lic. Conjuntas en Dcho. y Administración de Empresas & 12 & $83 \%$ \\
\hline OTROS & 3 & \\
\hline TOTAL & 158 & $48 \%$ \\
\hline
\end{tabular}

Puede parecer un contrasentido que estas universidades presenciales estén consiguiendo cifras tan altas de actividades en un campo virtual, sin embargo esto no significa que los profesores y el sistema estén en peligro y que todo se hará a distancia. Esta etapa intermedia sirve para educar al alumno en una nueva cultura del aprendizaje en la que tiene que mejorar su esfuerzo personal frente a las propuestas del profesor. Por su parte, este último deberá adaptar sus propuestas y canalizarlas hacia un entendimiento con los alumnos. Quien 
hace predicciones probablemente se equivoca, porque al menos en las dos primeras décadas de este siglo la docencia en las aulas seguirá teniendo la mayor parte de los alumnos. Las universidades como instituciones de vanguardia hacen bien al acercarse a metodologías que hacen más dinámica y efectiva la enseñanza. Con el paso del tiempo, es posible que las aulas se vacíen o al menos no estén tan masificadas como en la actualidad, pero para entonces las universidades ya habrán previsto mecanismos alternativos. Por eso es fundamental que no se queden atrás, que entren con decisión en el sistema a distancia para ser igual o más competitivas que cuando sólo existía la modalidad presencial.

\section{MODELOS DOCENTES EN BIBLIOTECOLOGÍA: CENTRO UNIVERSITARIO DE INVESTIGACIONES BIBLIOTECOLÓGICAS Y DEPARTAMENTO DE BIBLIOTECONOMÍA Y DOCUMENTACIÓN}

En el ámbito de la bibliotecología ya se han utilizado las tecnologías en la educación mixta y a distancia. En el caso del Centro Universitario de Investigaciones Bibliotecológicas (CUIB) se analizan y valoran los recursos que ya se han empleado en su campus de educación a distancia, y también las aportaciones hechas por el departamento de Biblioteconomía y Documentación de la Universidad Complutense de Madrid, el cual participó en ADA-Madrid y creó un campus virtual ByD para que los profesores utilizaran la tecnología en sus clases.

En este sentido, el CUIB ${ }^{33}$, además de dar asesoría y apoyo docente a instituciones, es corresponsable del posgrado de Bibliotecología y Estudios de la información de la Facultad de Filosofía y Letras en la UNAM. Para estar a la altura de las demandas tecnológicas el CUIB inició el desarrollo de herramientas de apoyo que le permitan impartir cursos a distancia a nivel de maestría, licenciatura y cursos de actualización. Para ello diseñó una aplicación basada en Internet que contempla dos puntos de vista y operaciones principales: la del profesor y la del alumno:

1. Profesor: le proporciona una estructura en la que puede mostrarles a los alumnos los elementos principales de un curso, nombre, objetivo, temario, programa de actividades, aspectos generales del profesor, antecedentes del curso, etcétera.

33 Datos facilitados por René Pérez Espinosa quien en su día puso en marcha la tecnología necesaria para hacer realidad este proyecto docente virtual. 
2. Alumno: le da acceso a la información del curso para que pueda comunicarse con el profesor y/o los alumnos, ya sea de forma síncrona o asíncrona, y obtener el material de apoyo necesario (material de origen digital) y los mecanismos que le permitan observar su avance en el curso.

El objetivo de la aplicación es proporcionar una estructura de apoyo que sirva para impartir cursos de manera semipresencial en diversos niveles académicos. Para ello se requiere que sea flexible en cuanto a los elementos que la componen y también en la plataforma de cómputo en la que se implante. Además, los cursos pueden formar parte de un plan de estudios o ser cursos independientes. Considerando la aplicación anterior se desarrolló un software denominado "espacio de aprendizaje" que se puede implantar en plataformas UNIX, Linux y Windows.

La estructura general tanto para los alumnos como para los profesores está formada por una sección titulada "presentación del curso" en la que se incluyen los objetivos generales y específicos, así como un temario, una bibliografía, diversas actividades a desarrollar, la creación de foros de discusión, la utilización de recursos de aprendizaje en formato digital, una carpeta para el alumno y la evaluación de sus actividades. En este sistema de educación para la bibliotecología, profesores y alumnos cumplen nuevos roles formativos. En el primer caso, el profesor puede dar de alta a los alumnos, asignar y modificar sus calificaciones, establecer y modificar criterios de evaluación, ofrecer actividades y recursos de aprendizaje, plantear tópicos en el foro de discusión y establecer la duración de cada una de las actividades entre otras cosas. Por su parte, el alumno cuenta con un espacio denominado "carpeta" en el que va ingresando los activos correspondientes a las actividades realizadas. Asimismo, puede consultar sus calificaciones personales, tener acceso a sus recursos de aprendizaje y participar en foros de discusión, como lo muestra la Figura 6, en los periodos que el profesor establezca.

Una de las herramientas que más se han utilizado y en la que se han tenido buenas experiencias de aprendizaje son los foros de discusión, ya que les permiten a los alumnos responder $\mathrm{y} / \mathrm{u}$ opinar sobre cuestionamientos planteados por el profesor, y pueden dar origen a nuevas discusiones generadas a partir de las opiniones vertidas. El foro está diseñado con una estructura jerárquica que permite la discusión a diferentes niveles (Figura 6). 


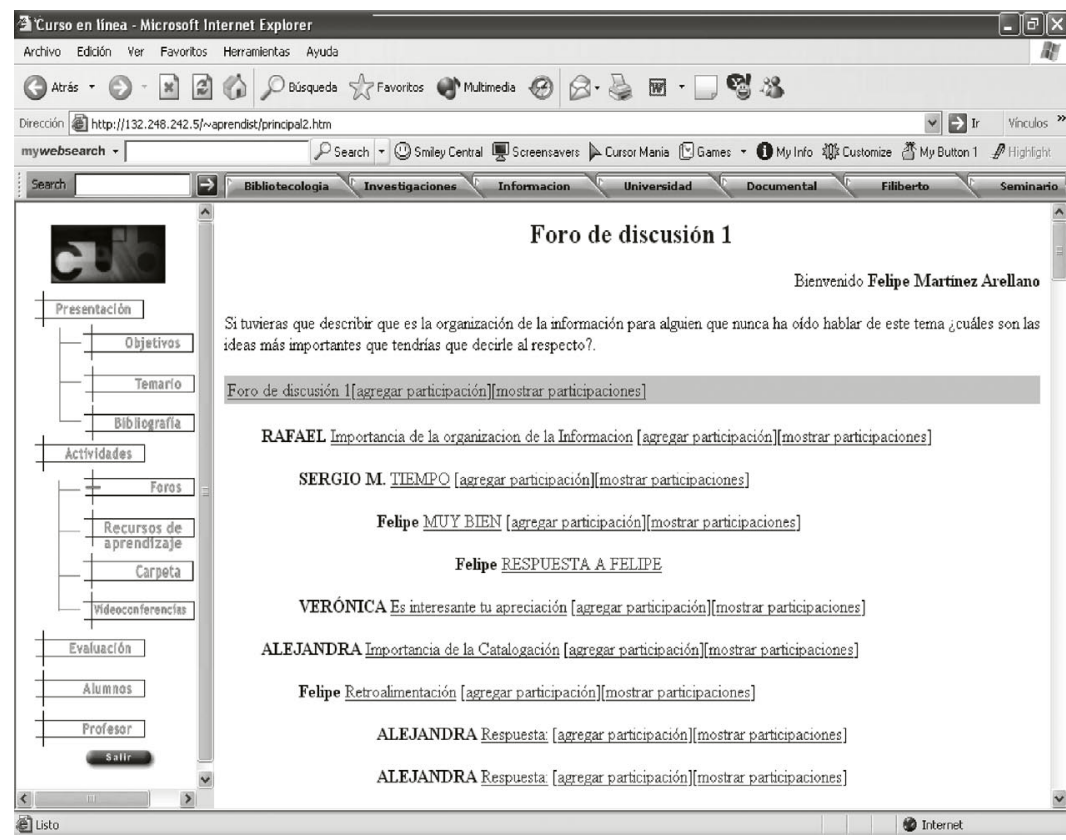

Figura 6. Foros contestados por los alumnos del campus virtual del CUIB.

En los cursos impartidos hasta el momento se han observado algunas situaciones que deberán mejorarse en los siguientes cursos programados: que tanto los alumnos como los profesores deberán establecer un ritmo constante de participación, lo cual conlleva una revisión constante de la información vertida en el espacio. Es crítico que el profesor tenga planteado -Figura 7- el esquema del curso desde un inicio y que los participantes tengan conocimiento del mismo, lo cual implica tener fechas, actividades, criterios de evaluación y objetivos muy bien definidos, y que no den lugar a ambigüedades.

Los alumnos deben organizar muy bien los tiempos en que realizan sus actividades y considerar los elementos que requieren, de manera que cuenten con éstos para poder hacer sus actividades de forma efectiva. Hay que establecer planes alternativos que le permitan, tanto a profesores como alumnos, paliar imprevistos como son la falta de acceso a Internet o problemas en los equipos donde se encuentre instalada la aplicación. Se prueba su nivel de aplicación considerando principalmente su aspecto operativo como una primera etapa; esto es, que el funcionamiento de la aplicación sea sencillo, que la navegación dentro de la herramienta sea funcional y adecuada, y que las actividades automatizadas sean precisas. Sin embargo una etapa futura considerará el aspecto de visualización y el diseño gráfico, el cual requiere de tres elementos críticos: 


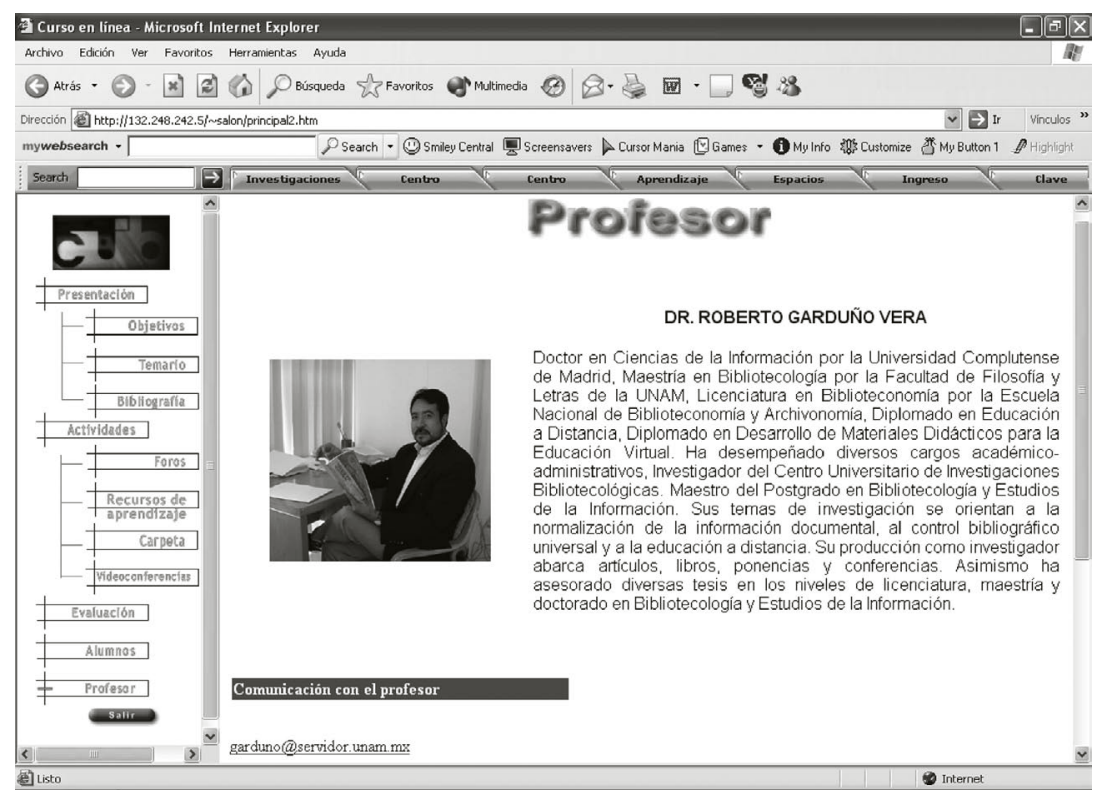

Figura 7. Sitio del profesor y actividades que se pueden realizar en el Campus.

1. Que sea agradable

2. Que sea sencillo

3. Que pueda ser utilizado con las diversas versiones de navegadores en diversos sistemas operativos

Por último, se ha pensado en utilizar herramientas de evaluación en tiempo real, pero esto no se ha concretado aún. Es éste un paso importante que hay que estudiar y sobre todo disponer de la tecnología necesaria para realizarlo. Hay que mencionar también a la Escuela Nacional de Biblioteconomía y Archivonomía (ENBA) ya que en el campo de la bibliotecología fue la pionera en ofrecer estudios a distancia y en la actualidad se mantiene como una escuela que mantiene amplias actividades educativas a distancia.Por su parte, el Departamento de Biblioteconomía y Documentación de la UCM colabora en el proyecto ADA-Madrid, una experiencia profesor-alumno en un sitio cerrado dentro de Internet que le ofrece a los profesores la posibilidad de crear recursos en ese sitio web. Esta primera experiencia se hizo a lo largo del curso 2003-04 y en ella participaron siete profesores del Departamento y tres de la Escuela de Biblioteconomía y Documentación. 


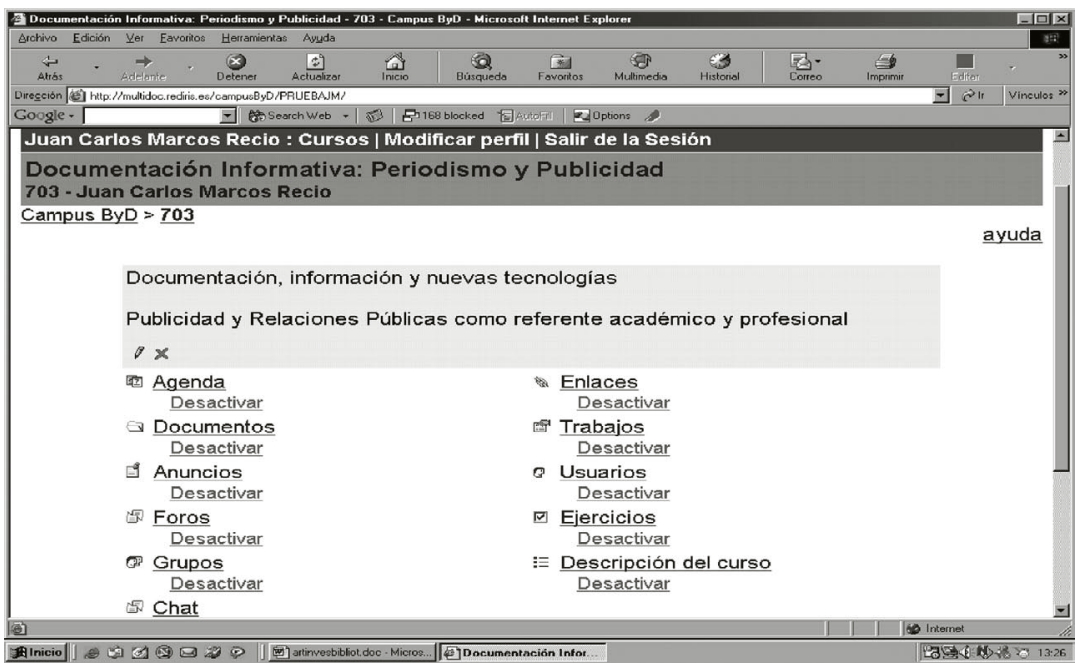

Figura 8. Opciones que ofrece para una asignatura el campus virtual de biblioteconomía y documentación.

Esta herramienta le permite al profesor colocar sus apuntes, sus ideas y los guiones de su clase dentro de la sección documentos. Tiene asimismo una agenda en la que anuncia las actividades a desarrollar en clase y un espacio de anuncios para otros eventos que quiera organizar. Por supuesto la interactividad está presente -ver figura 8-a través del chat, los foros y los grupos de discusión. Cuenta también con un espacio para generar enlaces de interés a sitios o artículos que el profesor considere que se deben leer. Dos secciones recogen las actividades prácticas del alumno: trabajos y ejercicios. El profesor deja a un lado el papel y los soportes cerrados, disquets que pueden llevar virus, o CDROM y corrige las prácticas en ese espacio, cosa que puede hacer en cualquier momento y desde cualquier lugar que tenga una conexión a Internet. Dentro de Usuarios el profesor puede crear grupos generales para el control docente o grupos particulares para distribuir las prácticas y los trabajos de curso. Se pueden crear tantos grupos como necesidades académicas se requieran.

Cuando el alumno llega por primera vez a una herramienta de estas características necesita información sobre cómo trabajar y cuáles deben ser los métodos de evaluación para su trabajo. Dentro de este sitio se formulan todas esas propuestas, así como los objetivos y logros que se conseguirán en Descripción del curso. Se trata de un referente para que el alumno se habitúe al trabajo, el estudio y la realización de actividades complementarias dentro de Internet. Por su parte el profesor tiene acceso a una serie de estadísticas que recogen de forma resumida las actuaciones de los alumnos, lo que le permite hacer un seguimiento personalizado de aquellos que se quedan rezagados y que deben mejorar. 
En todo caso esta herramienta no es específica de la bibliotecología, ni está adaptada al uso documental. Es un sitio que recoge actividades educativas que se pueden llevar a cabo a distancia en cualquiera de las temáticas docentes universitarias. Es un espacio global para muchas materias e instituciones y, una vez dentro, se puede adaptar a necesidades concretas de una asignatura si se implementan otros programas.

Hay otra opción que se pondrá en marcha a lo largo del curso 200405 y hacia la que algunos docentes del Departamento de Biblioteconomía y Documentación migrarán sus cursos, la plataforma del Campus Virtual de la Universidad Complutense ya citada con anterioridad, pues de esta forma verán reconocido su trabajo y hasta podrá ser considerado evaluable, ya que la actual herramienta al ser de uso del Departamento y de la Escuela de Biblioteconomía y Documentación ofrecía recursos pero no estaba avalada por la universidad como institución global. En menos de cinco años, la bibliotecología en España habrá asumido con mucha probabilidad el modelo general que propone la Universidad Complutense a través de su Campus Virtual, para lo cual utilizará una herramienta WebCT que se creó para todas las disciplinas, pero que desde los estudios de bibliotecología se irá perfilando y mejorando en los cursos, las prácticas y trabajos propios de esta especialidad.

\section{CONCLUSIONES: RETOS Y DESAFíOS DE LA EDUCACIÓN A DISTANCIA}

La actividad educativa es cambiante como la sociedad a la que le da servicio. Aunque esos cambios se experimentan muy lentamente, la realidad muestra que, en apenas una década, la universidad ha pasado de no tener ningún tipo de estudios a distancia, a configurar universidades que ofrecen sólo esa modalidad educativa. Toda transformación requiere un tiempo, pero con el impulso de las Tecnologías de la Información y la Comunicación este tiempo será menor.

En una década se han formulado tantas propuestas educativas que a estas alturas los principales puntos de debate se centran en comprobar si las instituciones políticas van a ofrecer los recursos para impartir y ofrecer educación a distancia, si las universidades apoyarán e incentivarán el trabajo de los profesores y si los alumnos llegarán con un nivel tecnológico adecuado. Estos tres sectores darán el impulso decisivo.

Los docentes tendrán que adaptarse a otra forma de impartir sus clases. Ya cuentan con multitud de recursos en línea que deben aprovechar. Y se formarán grupos de profesores de una misma especialidad o área temática para preparar los contenidos, las prácticas y el uso de la bibliografía 
correspondiente. Se fomenta ya una educación más compartida donde las ideas del profesor sean fruto del trabajo de un equipo de docentes, pero donde se respeta siempre la libertad de opinión del profesor. Hay que promover una interacción social que acerque el trabajo del profesor a los alumnos. El mayor problema puede plantearse en el desarrollo académico cuando se propongan los contenidos, al menos en las primeras fases de implementación de una asignatura. Luego será todo más sencillo, pero en los primeros cursos se le exigirá un esfuerzo mayor al docente. Sin embargo, se requiere un impulso por parte de la universidad.

Pasada ya la euforia inicial de estos primeros sistemas de educación a distancia experimentados en algunas universidades públicas, la mayoría de profesores sigue prefiriendo los sistemas tradicionales y desconfía de que la interactividad y las aportaciones que le hace el alumno al grupo, y las que hacen entre ellos, sean decisivas para su formación. Siguen creyendo que la civilización ha ido avanzando gracias a que ellos y quienes los precedieron a ellos fueron capaces de sintetizar el conocimiento y exponérselo a los alumnos. Es así como ha sido y funcionado para los tiempos de la revolución de la imprenta, pero en el siglo XXI el soporte principal ya no son los libros, sino la computadora, que a su vez puede ofrecer gracias a la ampliación de su memoria miles de libros y material docente, artículos escritos por otros profesores, etcétera. Algunos miran y evalúan, pero les falta un pequeño empujón, alguien que les reconozca otras maneras de impartir docencia. Será responsabilidad de la universidad ofrecerles a los docentes cursos de formación y capacitación de carácter general sobre la herramienta que deberán emplear en su trabajo. Aquí es necesario recordar la importancia de que sean sistemas normalizados y estandarizados porque esto le permitirá luego a ese profesor acceder a otros iguales o similares en su intercambio de contenidos o prácticas docentes.

Los alumnos son quienes habrán de asumir la mayor responsabilidad. Hasta ahora llegaban a clase en la universidad y escuchaban cada día un discurso más o menos coherente del profesor. Pasado un tiempo se examinaban en esa materia y con un trabajo final y algunas prácticas habían resuelto las asignaturas; así durante cuatro o cinco años que duraba su licenciatura. Ahora su actuación cambiará radicalmente; se convertirá en protagonista de los estudios; dejará de ser pasivo para convertirse en el motor principal de su educación, siempre bajo la atenta supervisión del profesor.

La adaptación del alumno ha de ser inmediata. Para ello, se le exigirá al gobierno una política educativa nacional en todos los niveles, para que cuando el interesado llegue a la educación superior no esté rezagado con respecto a la tecnología. Es precisamente durante las etapas iniciales cuando el esfuerzo 
habrá de ser mayor, pues desde sus primeros estudios habrá tenido que acostumbrarse a manejar computadoras. Así, su incorporación a la universidad, con trabajos docentes a distancia, resultará más sencilla. De esta forma el esfuerzo realizado por el profesor habrá de estar acompañado del que hace el alumno. Se trata de colectivizar sistemas de aprendizaje en los que se pedirá un esfuerzo de todos los actores implicados en la educación a distancia. Las universidades tendrán que garantizar ciertos niveles de conectividad para que el alumno pueda acceder al campus, en cualquier momento.

De manera global el presupuesto deberá cubrir las necesidades técnicas de los profesores y permitirle al alumno el acceso a la tecnología sin que tenga que hacer un desembolso importante. Esto exigirá la creación de redes fuera del ámbito universitario, pues una parte de los estudios se realizará desde casa o desde el trabajo. Así, no sólo se implica a una universidad sino a todo un país, el cual tendrá que garantizar el mantenimiento de una tecnología activa que funcione en el momento requerido por el alumno, cuando éste enfrente sus prácticas o cuando esté compartiendo con otros su opinión a través de un foro en tiempo real. Por su parte, el estado demandará de las universidades actuaciones conjuntas para evitar las repeticiones innecesarias de contenidos.

Una buena manera de evaluar y dar a conocer el trabajo y el esfuerzo de la educación a distancia es a través de publicaciones digitales. Las universidades habrán de crear, potenciar y dar a conocer revistas que analicen estos sistemas docentes. Los congresos, tanto en línea como presenciales, son un ejemplo claro de cómo los expertos están apoyando la docencia a distancia. En ellos se exponen los últimos avances y las proyecciones futuras que están intentando crear las universidades. Así, una parte importante de los contenidos de este trabajo proviene de ponencias y presentaciones en congresos a distancia celebrados en los primeros meses del 2004.

Por último, se requiere también que la biblioteca haga esfuerzos. Muchos materiales aún no están digitalizados. El alumno no ha de conformarse con lo que se le facilita en el curso a distancia sino obtener otros recursos en las bibliotecas tradicionales; al menos, hasta que las bibliotecas digitales dispongan también de fondos que les permitan una visión amplia del trabajo del alumno. Habrá que crear una red de bibliotecas digitales que den servicio desde distintos lugares de conexión para los alumnos a distancia.

Al final se impondrá un "nuevo paradigma educativo" como señalaba recientemente la directora académica del ILCE, Rosario Freixas Flores: 
[...] establecer el e-learning en tanto nuevo paradigma educativo es un soporte valiosísimo con un potencial enorme que puede transformar radicalmente la educación en cuanto al acceso y la equidad. ${ }^{34}$

La autora señala en esa misma entrevista que América Latina tiene aún algunas dificultades como las geográficas o la insuficiente infraestructura en comunicación, pero los primeros pasos ya se han dado.

\section{BIBLIOGRAFÍA:}

Almada de Ascencio, Margarita, "El acceso a la información y la universidad virtual: una perspectiva de políticas de información y educación", en La información en el inicio de la era electrónica. información sociedad y tecnología, Vol. 2, CUIB, 1998.

, "Los flujos de información electrónica y la educación del futuro", en Internet, metadatos y acceso a la información en biliotecas y redes en la era electrónica, Martínez A., F. F. y Escalona, L. Eds, CUIB, UNAM, 2000.

"Los flujos de información electrónica y la educación del futuro", en XVIII Coloquio Internacional de Investigación Bibliotecológica. El medio digital en el siglo XXI: retos y perspectivas para los bibliotecólogos, investigadores, educadores y editores, México, D.F. UNAM, Centro Universitario de Investigaciones Bibliotecológicas, 5-6 de octubre del 2002.

Amaya Ramírez, Miguel Ángel; Calva González, Juan José, "Uso de la tecnología en la educación bibliotecológica”, en Jornadas Mexicanas de Biblioteconomía, 31 de mayo 2000, Querétaro.

Badia, E., La educación en la red: actividades virtuales de enseñanza y aprendizaje, Barcelona: Piadós, 2004.

Chacón, Fabio, "Aproximación histórica a las tecnologías de la educación a distancia”, ponencia presentada en el 1 Seminario Internacional de Nuevas Tecnologías en Educación organizado por CEDIPROE, 1996.

Chacón, Fabio, El nuevo paradigma para el adiestramiento corporativo, Teleconferencia EDUDIST, 1998.

Diéguez, Jorge, "Normativas y estándares para el tratamiento de contenidos”, en Estándares y especificaciones tecnológicas para el e-learning, Congreso Online Educa Madrid, 2004.

34 Rosario Freixas Flores, "Hay que compartir experiencias y dejar de duplicar esfuerzos", en Elearning America latina, Entrevista publicada en el número 3, año 2, 10 de septiembre de 2004. http://www.elearningamericalatina.com/ediciónseptiembre1_2004/tr_1.php [Consultada: 10-09-2004]. 
Escalona Ríos, Lina, "La modalidad de educación abierta y a distancia de la Escuela Nacional de Biblioteconomía y Archivonomía: entrevista con el Lic. Guillermo García Olvera”, México: Liber, Vol. 2, Núm, 1 (ene.mar.)

Garduño Vera, Roberto, "Internet en la educación virtual: un enfoque desde la investigación y la enseñanza en bibliotecología”, en Investigación Bibliotecológica, archivonomía, bibliotecología e información. Vol. 18, no.36 (ene./jun. 2004). , Educación a distancia y bibliotecología, México: UNAM, Centro Universitario de Investigaciones Bibliotecológicas, 2003. "Educación bibliotecaria vía Internet", en Documentación de las Ciencias de la Información, Vol. 26, (2003).

Herrero Ricaño, Rodolfo, La educación a distancia en la Universidad Nacional Autónoma de México, México: UNAM, Centro Universitario de Investigaciones Bibliotecológicas, 1996.

Jitrik, Noé, Glosario de Educación Superior, México: Comité Interinstitucional para el Glosario y el Tesauro de Educación Superior, 1986. (Mecanografiado)

Lafuente López, Ramiro [et al], "La enseñanza de la bibliotecología digital en la modalidad de educación a distancia”, en: XXXI Jornadas Mexicanas de Biblioteconomía. 31 de mayo y 1 y 2 de junio del 2000.

López Roblero, Edgar Leonel, "Consideraciones para la creación de un programa de licenciatura en bibliotecología en el sistema abierto", México: AMBAC, 1986, en Jornadas Mexicanas de Biblioteconomía, Pachuca, 1985.

Moliner, María, Diccionario de uso del español, Madrid: Gredos, 2001.

Pérez Paz, Nahum, Las licenciaturas en biblioteconomía y en archivonomía en la modalidad abierta y a distancia, de la Escuela Nacional de Biblioteconomía y Archivonomía, México: Consejo Nacional para Asuntos Bibliotecarios de las Universidades Públicas Estatales, 1996.

Pérez Paz, Nahum, El sistema de educación a distancia de la Escuela Nacional de Biblioteconomía y Archivonomía, México: Consejo Nacional para Asuntos Bibliotecarios de las Universidades Públicas Estatales, 1997.

Pérez Paz, Nahum, La modalidad de educación abierta y a distancia de la Escuela Nacional de Biblioteconomía y Archivonomía, México: AMBAC ; Poder Ejecutivo del Estado de Morelos, 1997.

Pisanty Baruch, Alejandro, Distancia y presencia: nuevos paradigmas en educación a distancia. México: UNAM, Centro Universitario de Investigaciones Bibliotecológicas, 2001.

Ramírez Aguirre, Arnulfo, La escuela abierta: una posibilidad para resolver la necesidad de capacitación en biblioteconomía, México: AMBAC, 1976.

Rodríguez Gallardo, Adolfo, "Bibliotecología Mexicana: una visión global hacia el futuro", en Jornadas Mexicanas de Biblioteconomía, 31 de mayo de 2000, Querétaro. 
Sametz Remba, Linda, Bibliografía: guía de autoaprendizaje, México: Escuela Nacional de Biblioteconomía y Archivonomía, 1997.

Sánchez Telléz, María Isabel, Tecnología de redes y servicios de red, México: ENBA, 2000.

Taylor, J.C. (2004), “E-learning futures”, Plenary Session Presentation to the Annual Estonian Information Technology Foundation Conference "E-Learning - a challenge to higher education", Tallinn, Estonia,12 March, vía videoconference.

Taylor, J.C. (2004), "Increasing access to higher education through the application of appropriate models of distance education". Presented to the All African Ministers' Conference on Open Learning and Distance Education, Cape Town, South Africa, 1 - 4 February. 